\title{
Mechanisms of flexural flow folding of competent single-layers as evidenced by folded fibrous dolomite veins
}

\author{
Torremans Koen*, Muchez Philippe, Sintubin Manuel
}

\author{
Affiliations: Geodynamics and Geofluids Research Group, \\ Department of Earth and Environmental Sciences, KU Leuven; \\ Celestijnenlaan 200E, B-3001 Leuven, Belgium. \\ manuel.sintubin@ees.kuleuven.be, \\ philippe.muchez@ees.kuleuven.be
}

Corresponding author: Koen Torremans koen.torremans@ees.kuleuven.be Tel.: +32 16326448 +32

\author{
473667173 Celestijnenlaan 200E bus 24103001 Leuven \\ Belgium
}

Keywords
- Fibrous dolomite veins
- Flexural flow folding
- Strain distribution
- Vein fabric
- Viscosity contrast

\begin{abstract}
Flexural flow is thought unlikely to occur in naturally deformed, competent isotropic single-layers. In this study we discuss a particular case of folded bedding-parallel fibrous dolomite veins in shale, in which the internal strain pattern and microstructural deformation features provide new insights in the mechanisms enabling flexural flow folding. Strain in the pre-folding veins is accommodated by two main mechanisms: intracrystalline deformation by bending and intergranular deformation with bookshelf rotation of dolomite fibres. The initially orthogonal dolomite fibres allowed a reconstruction of the strain distribution across the folded veins. This analysis shows that the planar mechanical anisotropy created by the fibres causes the veins to approximate flexural flow. During folding, synkinematic veins overgrow the pre-folding fibrous dolomite veins. Microstructures and dolomite growth morphologies reflect growth during progressive fold evolution, with evidence for flexural slip at fold lock-up. Homogeneous flattening, as evidenced by disjunctive axial-planar cleavage, subsequently modified these folds from class $1 \mathrm{~B}$ to $1 \mathrm{C}$ folds. Our study shows that the internal vein fabric has a first-order influence on folding kinematics. Moreover, the fibrous dolomite veins show high viscosity contrasts with the shale matrix, essential in creating transient permeability for subsequent mineralising stages in the later synkinematic veins during progressive folding.
\end{abstract}

\section{Introduction}

The kinematics of folding of competent single-layers has been intensely studied, showing significant complexity in strain accommodating mechanisms during folding, primarily due to a complex interplay of layer thickness, rheology contrast, degree of anisotropy, progressive changes in mechanical properties, strain rate and other parameters (e.g. Ramsay, 1967; Fletcher, 1974; Shimamoto and Hara, 1976; Treagus and Treagus, 1981; Schmalholz and Podladchikov, 1999, 2001; Schmid and Podladchikov, 2006; Hobbs et al., 2008, 2010; Kocher et al., 2008; Huang et al., 2010; Schmid et al., 2010). Nevertheless, a number of ideal reference cases is put forward for the internal strain distribution in symmetrically buckled, competent, isotropic single-layers within a viscous or powerlaw matrix. These are typically tangential-longitudinal strain, flexural flow and flexural slip (Ramsay, 1967; Hudleston and Lan, 1993; Bastida et al., 2003; Bobillo-Ares et al., 2006; Twiss and Moores, 2007).

Natural examples of folded, competent, isotropic single-layers in an incompetent viscous matrix generally show a strain distribution compatible with dominant tangential-longitudinal strain (Hudleston and Treagus, 2010; Evans and Fischer, 2012). Using numerical modelling, Hudleston et al. (1996) demonstrated that only the aggregate response of a highly anisotropic medium may approximate that of pure flexural flow. However, extremely high anisotropy parallel to the shear plane is normally only seen in incompetent layers, such as slates or phyllites with a pervasive slaty cleavage fabric. This lead Hudleston et al. (1996) to question whether flexural flow actually occurs in naturally folded, competent single-layers.

In order to understand the kinematics and strain accommodating mechanisms during folding of single-layers in a viscous or power-law matrix, intensive numerical modelling efforts were carried out in the last decade (e.g. Schmalholz and Podladchikov, 2000, 2001; Kocher et al., 2006; Schmalholz, 2006, 2008; Hobbs et al., 2008, 2010; Schmid et al., 2010; Huang et al., 2010; Hobbs and Ord, 2012; Schmalholz and Schmid, 2012). Many of these studies investigate how anisotropy within single-layers and the geometry of multiple transversely isotropic layers influences the folding instability and kinematics (e.g. Lan and Hudleston, 1996; Fletcher, 2005; Toimil and Griera, 2007; Kocher et al., 2008). From these studies, it is clear that the assumption of mechanical isotropy within single layers is an oversimplification, often with important influence of anisotropy both along and across competent single-layers, or in an aggregate response. In addition, we know that the internal fabric of folded single-layers in nature, in particular that of veins, shows significant complexity (Zhang et al., 1993; Hippertt and Tohver, 2002; Kocher et al., 2006; Toimil and Fernández, 2007; Toimil and Griera, 2007). It is, though, to date still poorly understood how exactly the internal fabric influences folding. 
In this study we focus on folded bedding-parallel, fibrous dolomite veins in shale. We aim to constrain the fold kinematics by which strain is accommodated in these veins, quantify the internal strain distribution and estimate the rheology at the time of deformation. Because the initial fabric of the folded fibrous veins is known, it allows to study how the internal microfabric influences the folding mechanism and quantify how much the fabric controls strain accommodation during folding. The study thus contributes to a better understanding of the role of the internal fabric and anisotropy during folding of competent single-layers.

Finally, folding is important in creating transient permeability structures and the associated mobility of fluids. Therefore, a good understanding of strain-accommodating mechanisms during folding is necessary to constrain fluid mobility (Evans and Fischer, 2012). In this respect, the microstructural observations of this study can provide better insights in the origin/development of the well-constrained sediment-hosted copper-cobalt ore deposits in the study area (Brems et al., 2009; Muchez et al., 2010).

\section{Geological Setting}

The study area is situated in the region of the Nkana stratiform Cu-Co deposit, near Kitwe, Zambia (Fig. 1; Mendelsohn, 1961a; François, 1974; Thieme and Johnson, 1981). The rocks belong to the Neoproterozoic Katanga Supergroup of the Central African Copperbelt, further subdivided into Roan, Nguba and Kundulungu Groups (Cailteux et al., 2005; Bull et al., 2011). They were deformed during the Pan-African, Lufilian orogeny, dated at $560 \mathrm{Ma}$ to 500 Ma (Porada and Berhorst, 2000; Hitzman et al., 2012). Peak regional metamorphism, reaching upper greenschist to lower amphibolites facies, occurred $~ 530 \mathrm{Ma}$ (John et al., 2004; Rainaud et al., 2005; Selley et al., 2005).

The Nkana deposit is situated in the southeastern limb of the Chambishi synformal basin, amidst the Kafue basement inlier (Fig. 1). Folding at the Nkana deposit is poly-harmonic with multiple orders of folding ranging from $1^{\text {st }}$ order folding at basin scale (Croaker, 2011) over $2^{\text {nd }}$ order hectometre-scale folds to $3^{\text {rd }}$ order metre-scale parasitic folding in the more competent units. Folding at the $2^{\text {nd }}$ and $3^{\text {rd }}$ order is by doubly plunging tight to isoclinals folds.

The veins described in this study occur in the Copperbelt Orebody Member of the Katanga Supergroup. This member represents the first transgressive stage overlying siliciclastic red-bed sediments of the Mindola Clastics Formation, related to continental rifting (Selley et al., 2005; Bull et al., 2011). The Copperbelt Orebody Member is a carbonaceous shale to siltstone with a pronounced shaly fabric at Nkana Central and South (Fig. 1). A strong bedding-parallel $S_{1}$ cleavage is developed in this carbonaceous shale lithofacies. Conversely, an axial planar $S_{2}$ cleavage is in general only weakly developed. However, in some higher-strain parts of Nkana South and Nkana Central, this $S_{2}$ cleavage is more strongly developed. Overlying the Copperbelt Orebody Member is a layer-cake stratigraphy of siliciclastics, dolomites and evaporates (Selley et al., 2005).

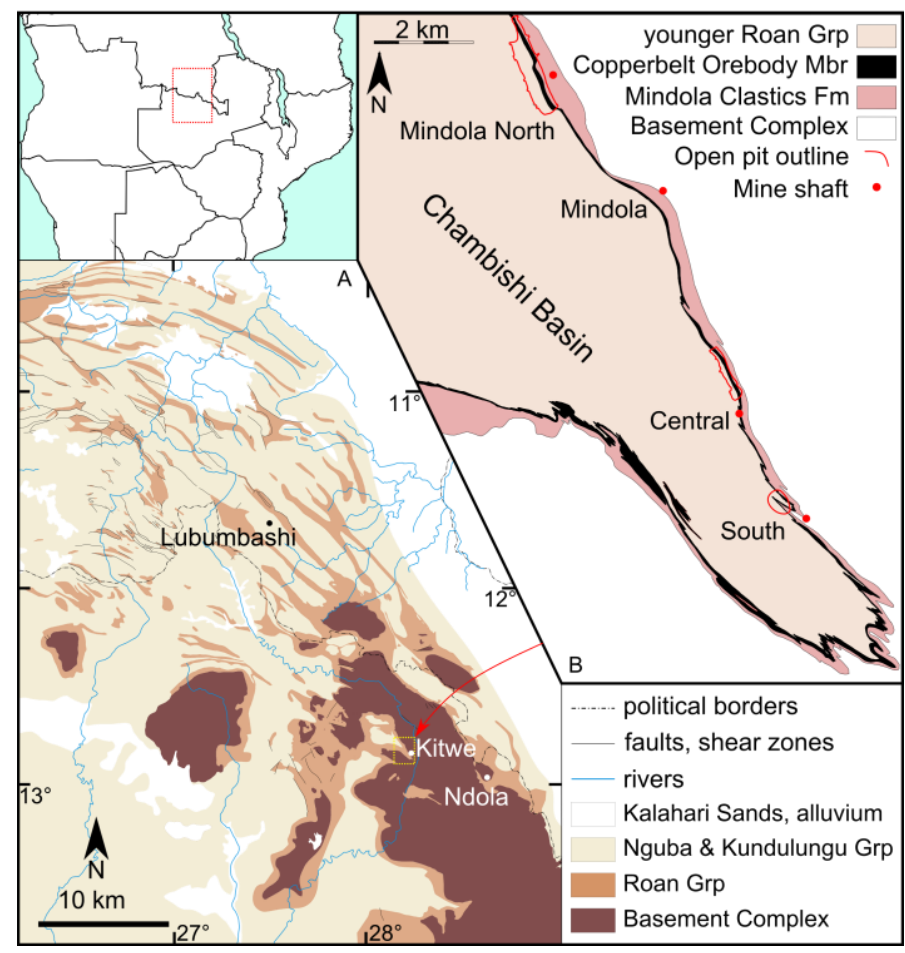

Fig. 1. (A) Schematic geological map showing the Central African Copperbelt, straddling the border between Zambia and the Democratic Republic of Congo. Geology is compiled from several sources (Mendelsohn, 1961a; François, 1974; Thieme and Johnson, 1981). The inset shows the position of this map in Central Africa. (B) Geological map of the southeast end of the Chambishi synformal basin, modified after an unpublished 2008 geological map of Mopani Copper Mines Plc. Four mine shafts and three open pits are indicated. Mbr: Member; Fm: Formation; Grp: Group.

\section{Vein generations}

Several vein generations occur in the deposit, previously studied with respect to the metallogenetic model of the ore deposit (Brems et al., 2009), the geochemistry of Cu-Co mineralising fluids (Muchez et al., 2010), REEY characteristics of the gangue carbonates (Debruyne et al., 2013) and the source of metals (Van Wilderode et al., 2013). Veins are most abundant in the carbonaceous shale to siltstone facies in the south of the Nkana deposit (Fig. 1).

In this study, we focus on the two earliest vein generations at Nkana. The earliest, type I veins are pre-folding, beddingparallel fibrous dolomite veins (Fig. 2). These monomineralic veins are continuous for several meters along strike. A second bedding-parallel generation, type II veins, is typically overgrowing type I veins, but also occurs as separate veins. Contacts of type II veins with the host rock are generally tortuous. 


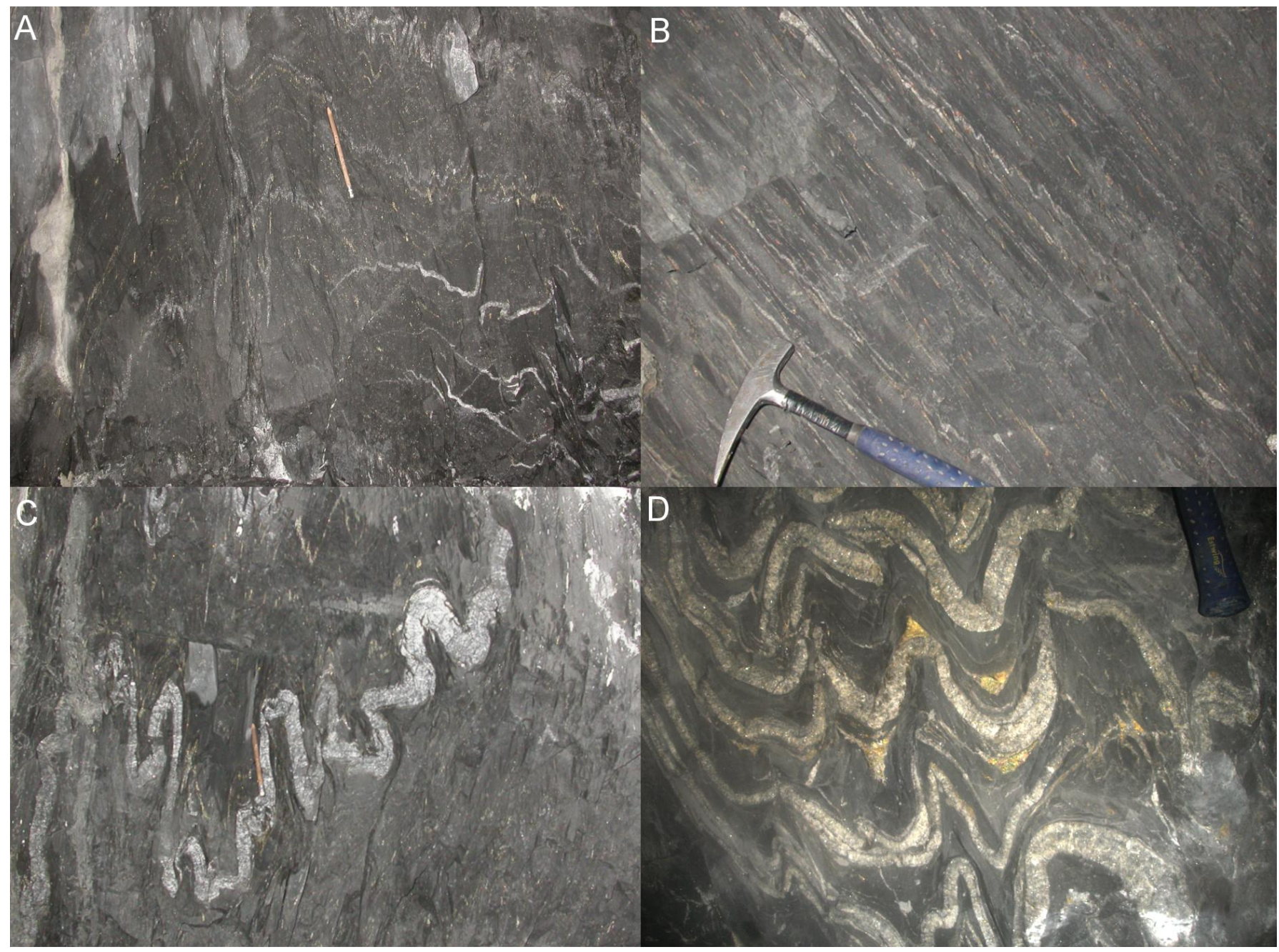

Fig. 2. Folded bedding-parallel veins at Nkana South. All outcrops are sub-vertical in WSW-ENE oriented crosscuts, perpendicular to the strike of $S_{1}$. (A) Tight to ptygmatic polyharmonic $4^{\text {th }}$ order folds decorate a $3^{\text {rd }}$ order antiformal structure. Fold axial planes are upright and sub-parallel to that of the $3^{\text {rd }}$ order fold (parallel to pencil). A disjunctive cleavage is developed, causing contrasting sinistral and dextral apparent displacements of buckled veins along axial cleavage planes. (B) Strongly asymmetric parasitic lowamplitude folds of thin type I veins with $S_{1}$ cleavage dipping 45NE. (C) Single-layer fold of a $4 \mathrm{~cm}$ thick type I vein. (D) Saddle reef accumulation of chalcopyrite, minor dolomite and quartz in type // veins between folded multilayer type I veins, near syn- and antiformal hinges.

\section{Mineralogy and growth morphologies of type I and II veins}

Petrographic and microstructural observations were carried out on 82 oriented thin sections that were obtained in a new field campaign (2012), in addition to 76 thin sections available from an extensive sample collection of two previous studies at Nkana (Brems et al., 2009; Muchez et al., 2010). Cold cathode luminescence $(\mathrm{CL})$ was carried out using a Techosyn Cold Cathode Luminescence Model 8200 Mk II (KU Leuven) combined with a Nikon microscope and a ProgRes C10 image capturing system. Working conditions were between 7 to 13 $\mathrm{kV}$ and 400 to $900 \mu \mathrm{A}$ with a beam width of $5 \mathrm{~mm}$ at a vacuum of $5.5 \mathrm{~Pa}$. Image capture time varied greatly to represent the view under the microscope, and images in this paper have exposure time ca. $2000 \mathrm{~ms}$ in a darkroom. Samples were stained with Alizarine Red-S and K-hexacyanoferrate to examine Fe-content and type of carbonates (cf. Dickson, 1966).

Type I veins are monomineralic veins, solely composed of ferroan dolomite fibres. The dolomite fibres are sub- orthogonal to the vein wall to within 5 degrees deviance in vein segments that are not macroscopically deformed by folding, shearing or boudinage and that show only minor microscopic deformation features (Fig. 3A). A range of vein growth morphologies is observed, from symmetric antitaxial with a pronounced median surface (Fig. 3B), over increasingly more asymmetric antitaxial (Fig. 3A) up to completely asymmetric unidirectional fibrous veins with a single growth surface - also termed unitaxial (cf. terminological discussions in Passchier and Trouw, 2005; Bons et al., 2012 and references therein). Growth morphologies are often transitional between these end-member cases. Dolomite grains show small but quantifiable growth competition (Fig. 3) with aspect ratios of $>$ 10:1, classifying them as fibres, although elongate-blocky grains are sometimes found in thinner veins (sensu Bons and Montenari, 2005). Vein walls reveal extremely low tortuosity. Where type I veins are overgrown by later generations, this vein-vein contact is also remarkably smooth and parallel to local $S_{0} / S_{1}$ (Fig. 3A). All type I veins show dull to occasionally bright yellowish brown luminescence (Fig. 4B). 


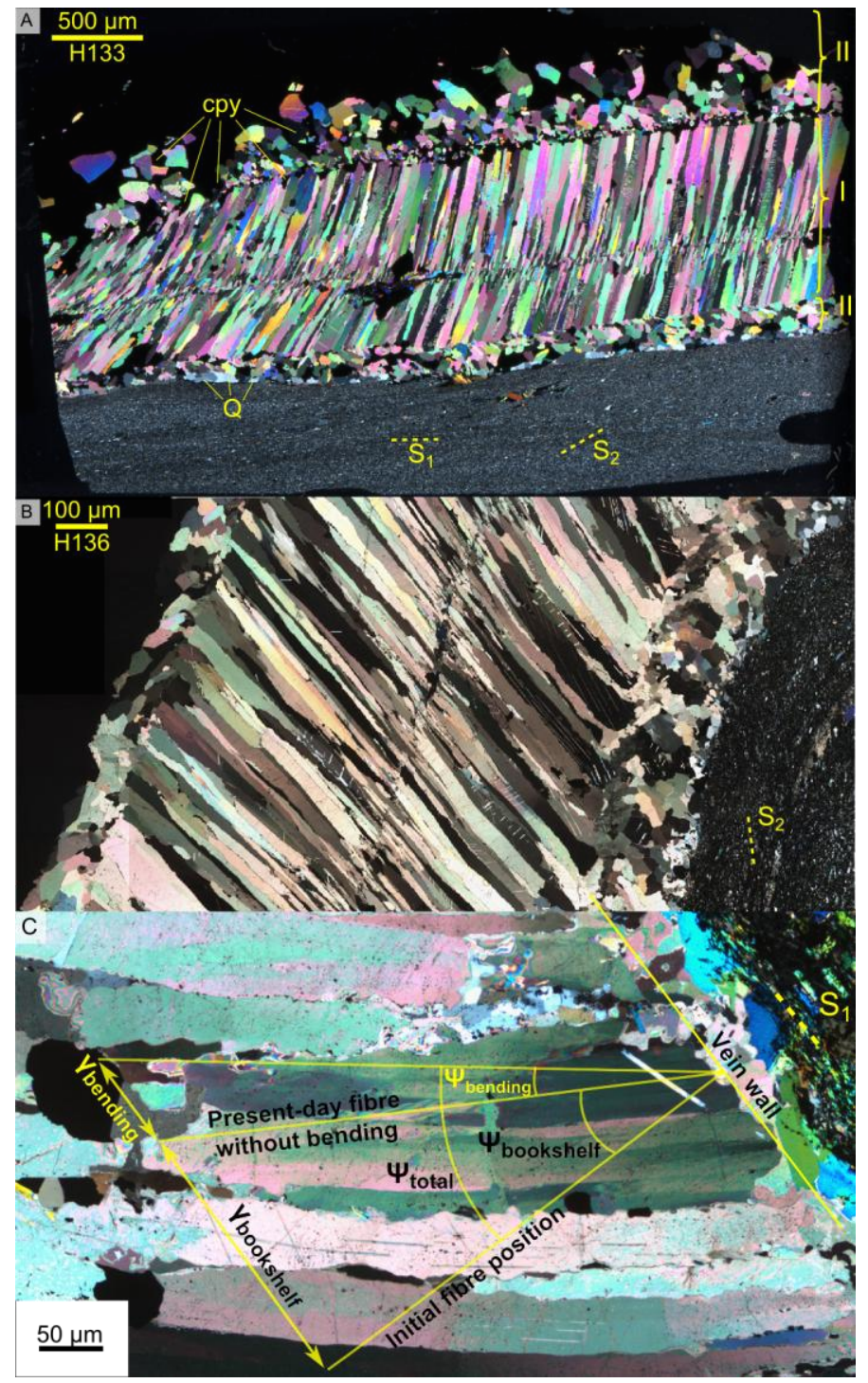

Fig. 3. Photomicrographs under crossed polars. (A) Antitaxial fibrous dolomite in type I vein overgrown by sub- to euhedral blocky dolomite, quartz (Q) and chalcopyrite (cpy). (B) Blocky to elongate-blocky type II dolomite and quartz overgrowing a single-layer folded antitaxial type I vein (H136 in Fig. 8). Fold hinge is to the top right. (C) Deformation of type I dolomite fibres is through a combination of intracrystalline deformation by bending and bookshelf rotation, with corresponding shear angle $\psi$ and shear $\gamma . \psi_{\text {bending }}$ is defined as the angle caused by bending of an initially straight fibre between its start-and endpoint. Type I fibre edges are recrystallised in some cases, as observed from type // CL hues and chalcopyrite along fibre edges, yielding somewhat more serrated grain boundaries in this image. The position of Fig. $3 \mathrm{C}$ within the fold is shown in Fig. 8.

Type II bedding-parallel veins often sandwich a type I vein (Fig. 3). They are composed of ferroan dolomite, Cu-Co sulphides, quartz, biotite and muscovite. The type II dolomite is invariably much duller luminescent than that of the type I fibres, always showing variable ranges of dull chocolate brown to dark red luminescence (cf. Figs. 4 and 6). This can serve as a diagnostic property, as the change from type I to type II veins is not always clear macroscopically or under the polarised microscope (e.g. Figs. 6). The dolomite in type II veins occurs in a variety of growth morphologies, as euhedral blocky or elongate-blocky grains (Figs. 3 and 5C), or more rarely as curved fibrous (Fig. 5C) or slickenfibre growth morphologies (Fig. 4A). Often, multiple growth morphologies sequentially follow each other within a single type II vein (e.g. Figs. 4 and $5)$. Despite the morphological variety, type II gangue dolomite is generally much more sub- to euhedral blocky as opposed to type I fibres.

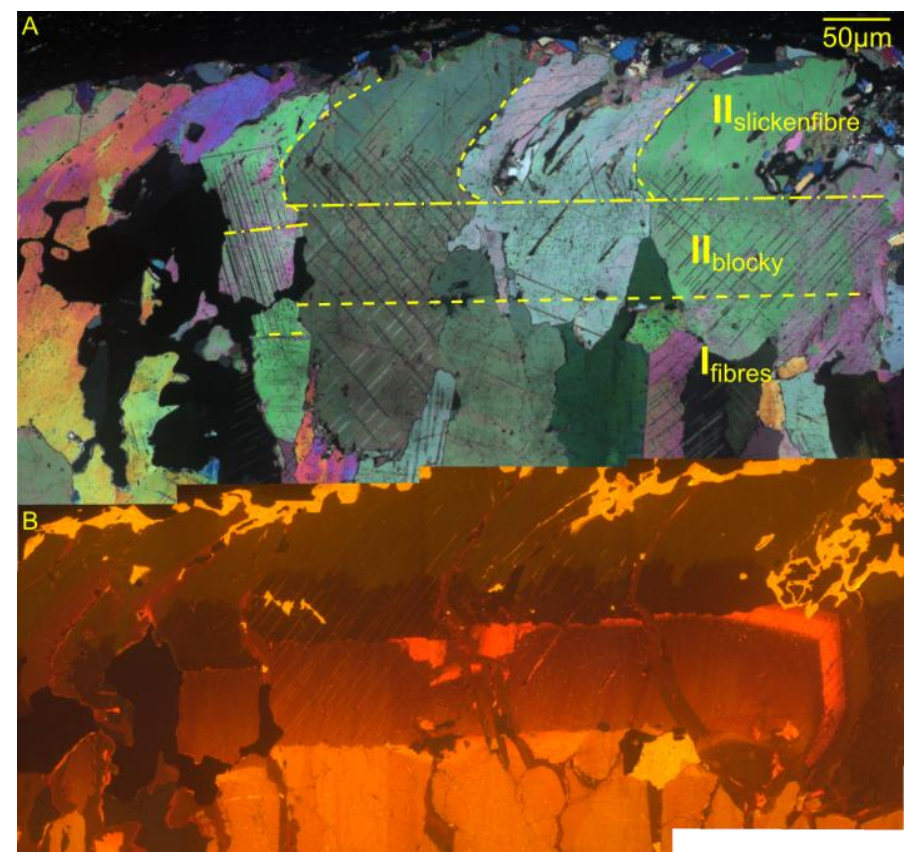

Fig. 4. Growth morphologies of type II dolomite, under crossed polars $(A)$ and $C L(B)$, that are optically continuous with type I dolomite under plain polarised light. The type I - II contact is straight and first growth of type II dolomite shows euhedral blocky dolomite with well-developed growth facets as evidenced from the zoned CL pattern. This first zoned generation is cut off by a second blocky dolomite generation gradually changing to strongly curved dolomite, forming slickenfibres with reverse slip sense. See Fig. 5C for location (white dashed box) 


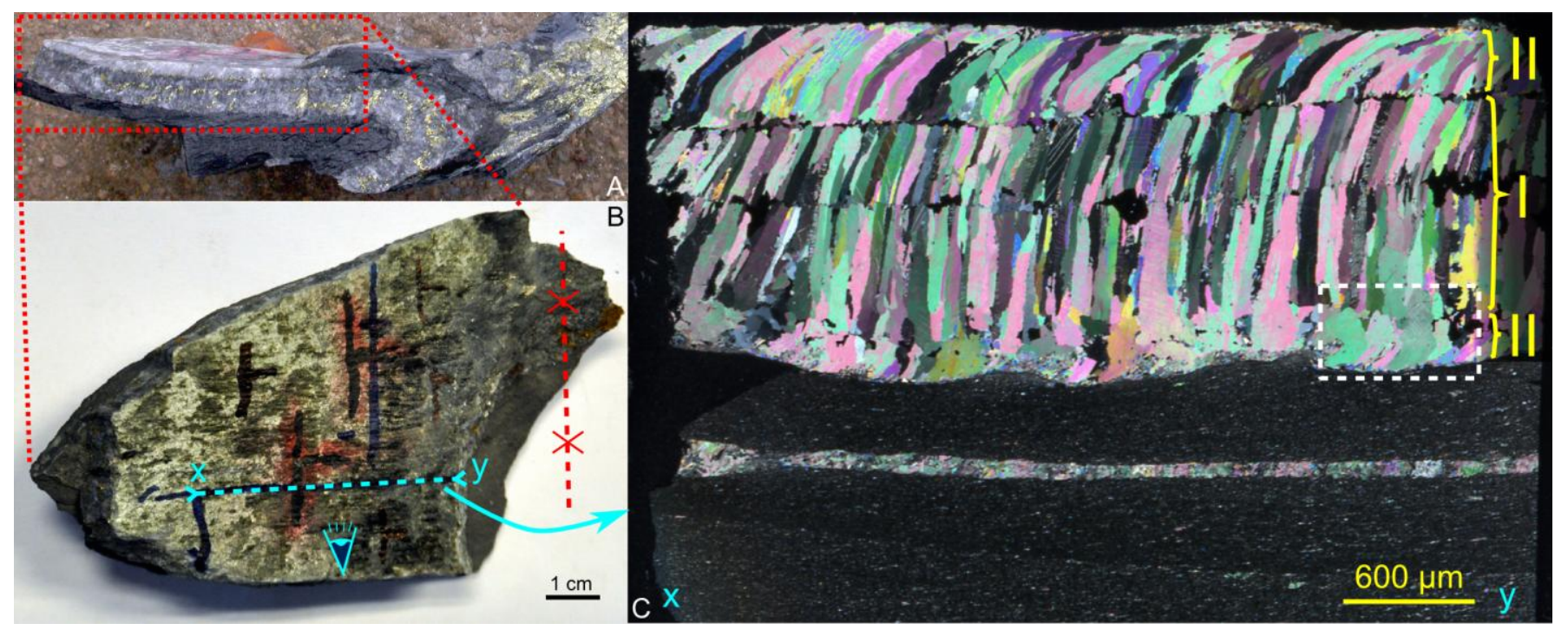

Fig. 5. (A) Single-layer folded antitaxial type I vein sandwiched between overgrowths of milky-white type II veins. (B) Top view of hand specimen, showing chlorite slickenlines. (C) Thin section under crossed polars with the fold hinge towards the right. Fibres are ferroan dolomite and opaque phase is chalcopyrite. The vein walls are lined by muscovite and chlorite slickenlines perpendicular to the fold hinge line (in red). Area within white dashed lines is shown in Fig. 4.

The evolution in the type II veins towards blocky euhedral morphologies often coincides with intense sulphide mineralisation. A clear trail of solid inclusions of dust, $\mathrm{Cu}-\mathrm{Co}$ sulphides or host-rock material frequently occurs along the contact between type I and type II veins (Figs. 3A and 6). The type II veins carry important amounts of $\mathrm{Cu}$ sulphides as opposed to the barren monomineralic dolomite type I veins (Figs. $3 \mathrm{~A}$ and 5 ). In those rare cases where $\mathrm{Cu}$-Co sulphides occur within the fibrous type I vein, they are always situated close to the median line or host rock and accompanied by later phases such as authigenic quartz, muscovite or type II dull brown to red luminescent dolomite, all of which have recrystallised or replaced the original fibres (Figs. 4 and 6B).
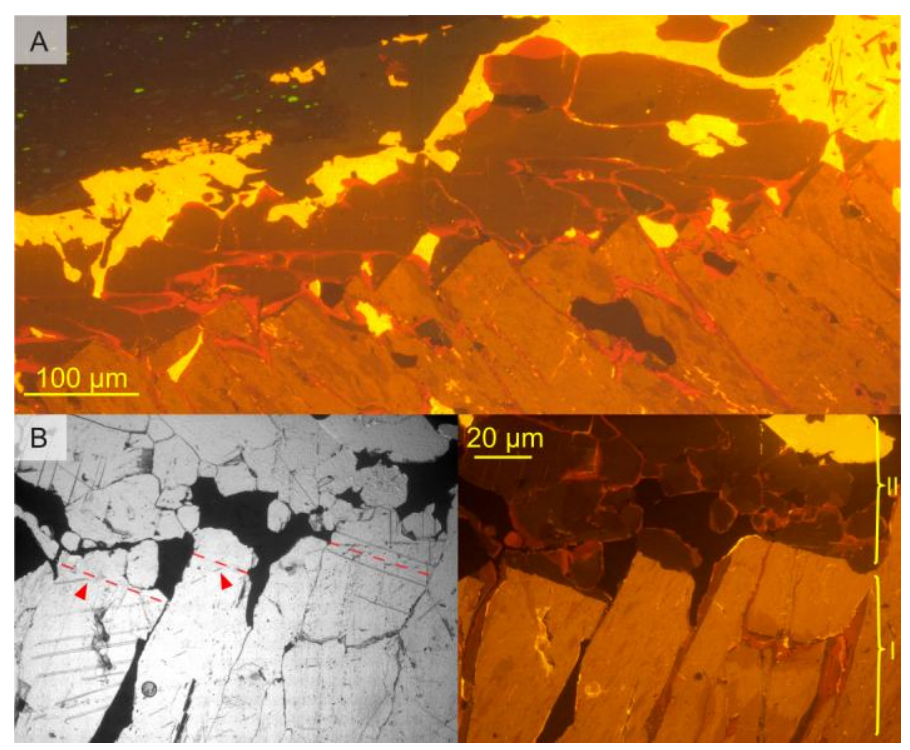

Fig. 6. (A) CL image showing bookshelf rotation of dull orange luminescent type I fibres in the $X Z$ plane of displacement (see Fig. 9A) and brown to dark red dull luminescent type II dolomite, in the limbs of single-layer folds. Bright yellow luminescent calcite is later alteration. (B) Transition between type I and II dolomite showing bookshelf rotation under plane polarised light and under CL.

\section{Geometries of deformed veins}

\subsection{Deformation styles of type / veins}

The particular deformation style of type I veins is a function of their position within $2^{\text {nd }}$ and $3^{\text {rd }}$ order folds and the relative angle between bedding-parallel $S_{1}$ foliation and axial-planar $S_{2}$ foliation. Type I veins are polyharmonically folded as $4^{\text {th }}$ order parasitic folds across $3^{\text {rd }}$ order sub-decametre scale folds, both as single-layer isolated folds (Figs. $2 \mathrm{~A}$ to $2 \mathrm{C}$ ) or as multilayer fold sequences (2D). Single-layer folds can be very tightly to ptygmatically folded, generally with wavelengths under $10 \mathrm{~cm}$ (Fig. 2C). Multilayer fold sequences range from disharmonic (Fig. 2D) over poly-harmonic to harmonic folds. Fold amplitudes in most multilayer systems are very high relative to single-layer folds of similar thickness and wavelength. The multilayer amplitudes decrease as the spacing between veins decreases.

With increasing dips, starting from ca. $20^{\circ}$ to $50^{\circ}$, the parasitic fold amplitude decreases and fold asymmetry increases away from fold hinges of lower-order folds (compare Figs. 2A and $2 B)$. Where bedding is steep along $2^{\text {nd }}$ or $3^{\text {rd }}$ order folds $\left(>65^{\circ}\right)$ bedding-parallel shearing occurs rather frequently, especially when $S_{1}$ is at a low angle to a steeply dipping $S_{2}$ (Fig. 7). Shear zones are difficult to continue macroscopically within the host rock and seem to die out in the matrix (Fig. 7). Shear displacements are generally under $20 \mathrm{~cm}$. Both reverse and normal faults are observed, which is not unexpected if the shearing is at a low angle to the bedding. These shear zones cause duplex structures of type I vein slabs (Fig. 7). The duplex structures generally only form if veins are not folded or folded at very low amplitude/wavelength ratio. In this last case, shear zones are not subsequently folded and crosscut the folds.

Macroscopically undeformed type I veins are mainly present in steeply dipping sequences. Occasional pinch-and-swell or boudinage segmentation of type I veins is observed in cases where limbs are steep to locally overturned. 


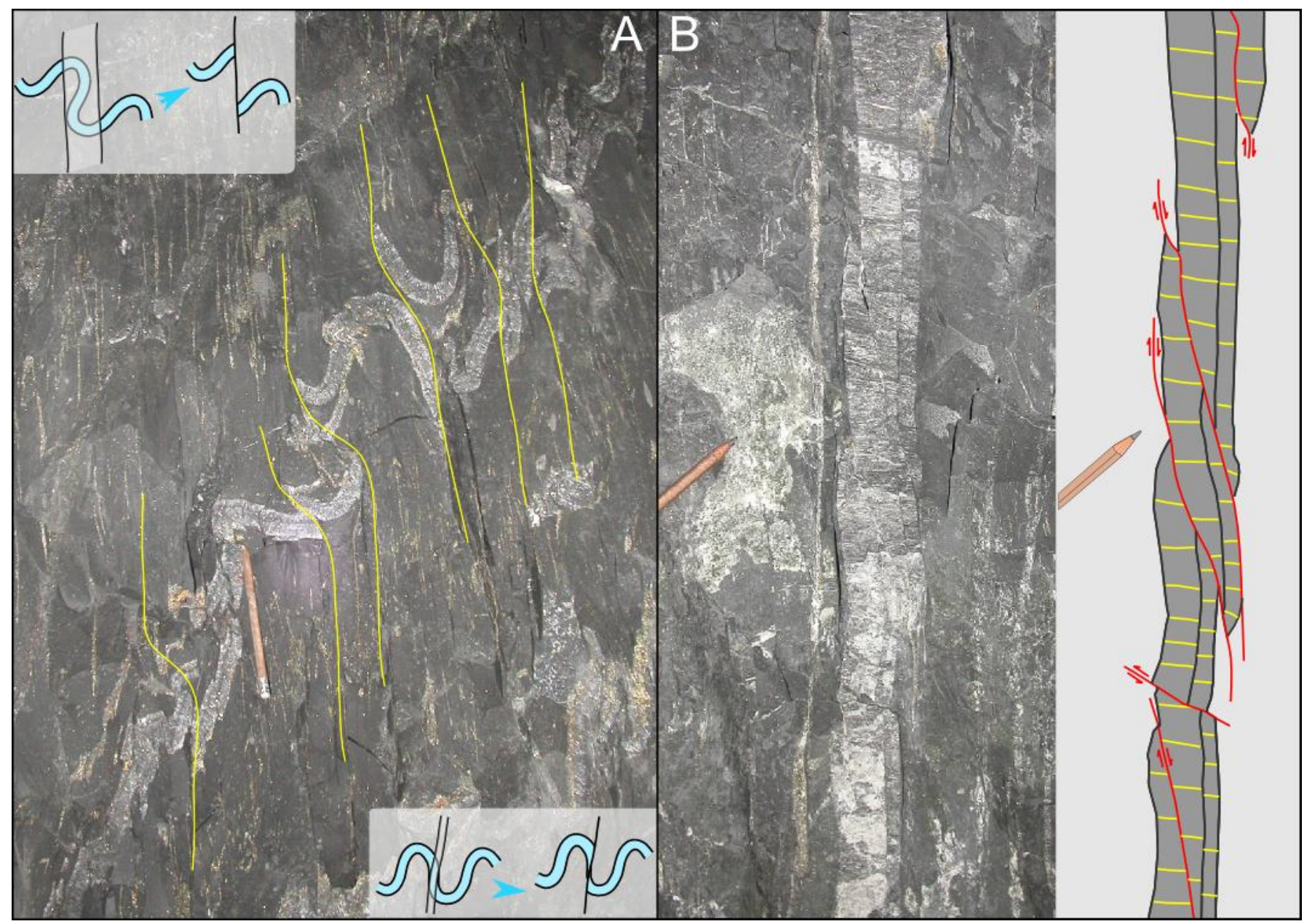

Fig. 7. Sub-vertical mining face perpendicular to the strike of $S_{1}$ and $S_{2}$ cleavage and fold hinge lines. (A) Highly curved anastomosing disjunctive $S_{2}$-cleavage planes, lined with $\mathrm{Cu}$-Co sulphides, micas and chlorite. The cleavage planes crosscut $4^{\text {th }}$ order folded type I veins, causing contrasting apparent displacements up to $10 \mathrm{~cm}$. Pencil is parallel to disseminated micas and sulphides in the host-rock matrix aligned along $S_{2}$ cleavage. (B) Duplex fault system of type I veins. $S_{1}$ bedding-parallel cleavage is vertical and at a low angle or parallel to the $S_{2}$ axial-planar cleavage.

\subsection{Slickenfibres and slickenlines on the vein-shale contact}

Type I and II veins occasionally reveal evidence for slip along the vein-host rock interface, as evidenced by mica, chlorite and dolomite slickenfibres with well-developed concomitant slickenline lineations (Figs. 4 and 5). Duplex horizons are often straddled by slickenfibres and slickenline lineations as well. Conversely, little to no slickenlines or -fibres were observed near fold hinges of $4^{\text {th }}$ order folded type I veins (Figs. 3B and 8). Where the slickenside surfaces were exposed in outcrop, the orientation of the slickenline lineations is sub-orthogonal to the fold hinge lines (Fig. 5). The lineation caused by dolomite slickenfibre step edges is usually sub-parallel to the local fold hinges (e.g. into the field of view of the thin section in Fig. 5).

\subsection{Disjunctive axial-planar $S_{2}$ cleavage}

In the high-strain parts of Nkana South and Central (Fig. 1), a disjunctive $S_{2}$ cleavage crosscuts the folded type I veins, generally at a high angle to the fold train (Fig. 7A). These cleavage planes are strongly anastomosing and reveal a spacing often up to 10 to $20 \mathrm{~cm}$. Contrasting displacements are observed along any given disjunctive cleavage plane crosscutting folded type I veins, as shown in Fig. 7A. In some cases, apparent displacements are quite high, up to $20 \mathrm{~cm}$.

\subsection{Saddle reefs}

Type II veins can show saddle reef structures near the fold hinges of the folded type I veins. These saddle reef structures most often occur in multilayer systems (2D), where thickness variation in the saddle reefs is quite often extreme as exemplified by the milky white dolomite accumulation in Fig. 5. Commonly, important accumulation of sulphide minerals is concomitant with the type II dolomite in these hinges (Fig. 2D), as already noted by Brems et al. (2009) and Muchez et al. (2010).

\section{Microfabrics of folded veins}

\subsection{Microfabric and microstructures in type I veins}

Strain in the folded single-layer veins is mainly accommodated by a combination of both intracrystalline and intergranular deformation in the dolomite fibres. In fold hinges only a limited amount of strain is present. There is no evidence for dilation of the outer arc, no large 'extrados' infill of later dolomite generations under cathodoluminescence, neither is there any indication for strong localised contraction in the inner arcs of the fold hinges through dissolution seams, stylolites, increased twinning, more intense grain boundary mobility, recovery processes or other intracrystalline deformation features (Fig. 8). 


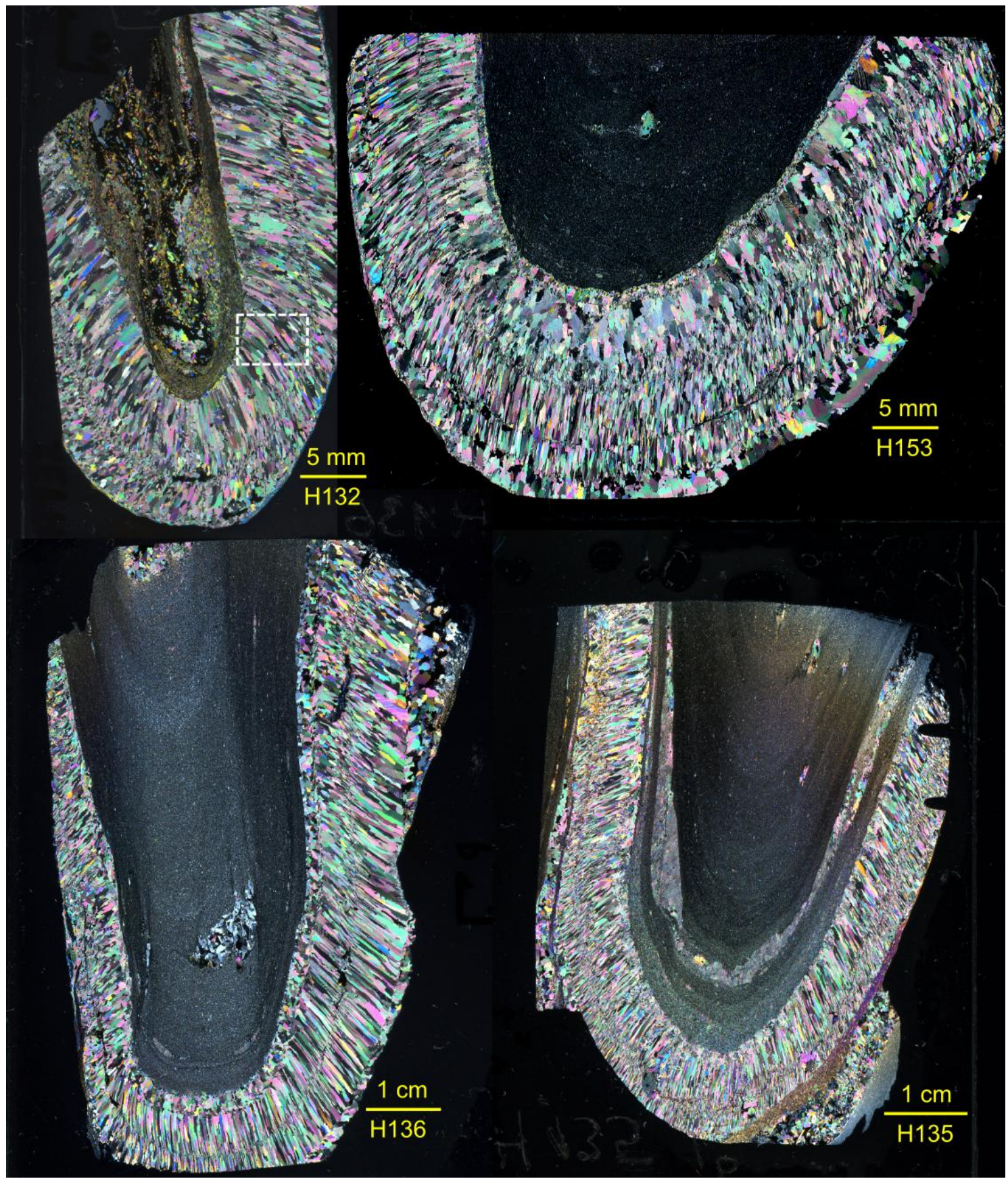

Fig. 8. Crossed-polars thin section scans of four well-oriented and representative folded veins used in measurements to produce Figs. 10 to 15. Sections were cut perpendicular to local fold hinge lines (XZ plane of displacement; Fig. 9B). The white rectangle indicates the area pictured in Fig. 3C.

\subsubsection{Intergranular deformation microstructures}

Abundant intergranular deformation occurs in the form of collective deviation of dolomite fibres relative to the orthogonal position, yielding bookshelf geometries (Fig. 6). The bookshelf geometries are most easily observed near the transition of fibrous type I dolomite and elongate-blocky to blocky type II overgrowths. Under $\mathrm{CL}$, an abrupt change from dull orange luminescent type I dolomite to dull dark red luminescent type II overgrowth is apparent (Fig. 6). Where fibres show a bookshelf geometry, this change in luminescence is always arranged en echelon in neighbouring fibres, whilst remaining remarkably straight and perfectly perpendicular to the fibre long axis, as illustrated in Fig. 6 and schematically in Fig. 9. The bookshelf geometries can also readily be observed on vein walls of type I veins without type Il overgrowths, but only in cases where later alteration in the veins is minor. These microstructures are interpreted as a collective rotation of fibres along parallel shear planes, in this case the low tortuosity grain boundaries, termed bookshelf rotation (cf. Mandl, 1987).

Bookshelf rotation of dolomite fibres occurs in the $X Z$ plane of displacement relative to the fold displacement framework (Fig. 9). The fibre rotation occurs in equal amounts on both vein walls of antitaxial type I veins as seen in Fig. 3B. The rotation becomes more intense as the layer inclination relative to the fold axial plane increases, as shown in Figure 8, but is also visible in segments that are farther away from the fold hinges (Fig. 3A). The bookshelf geometry is, however, conspicuously absent in the fold hinges (Fig. 8). The sense of bookshelf rotation is opposite in both limbs of a folds (Figs. 8 and $9 \mathrm{~B}$ ). Where folded veins are symmetrical, variation in fibre 
attitude is also symmetrical across the fold hinges (Fig. 8). Fibres are always orthogonal to the layer in the fold hinges.

Near the edges of type I veins, the bookshelf rotation is accompanied either by local deformation of the host-rock or by concomitant growth of type II dolomite (Fig. 6). Some type I fibres have grown optically continuous into the type II elongate-blocky to blocky overgrowth under polarised light (Figs. 5 to 6 ). The type II dolomite generally reveals a portion of continued fibre growth, up to a certain horizon of change in growth morphology, from fibrous to elongate-blocky or blocky dolomite (Figs. 3B, 4 and 6). Under $\mathrm{CL}$, grain boundaries between bookshelves occasionally reveal a recrystallised zone of type II dolomite with concomitant sulphides along the boundaries, often up to the median line (Figs. 3B, 4 and 6). Some twin generations in the fibres do not continue across the type I-II contact in CL colour, whereas others do. The latter are hence interpreted to postdate growth of type II overgrowths (Figs. 4 and 6B). Unfortunately, later alteration often obscures observations near the vein wall (e.g. the bright yellow luminescent calcite in Figs. 4 and 6 or vein wall alteration in Fig. 3C).

\subsubsection{Intracrystalline deformation microstructures}

Some dolomite fibres are strongly curved in the middle of the vein. These curved parts show concomitant intracrystalline deformation (Fig. 3C). In general, the intracrystalline deformation microstructures are found to be most common and intense in the fold sections with the highest curvature (Fig. 3C). Conversely, in relatively undeformed veins, the intensity of intracrystalline deformation is much lower (Fig. 3A).

Firstly, undulatory extinction occurs in the fibres. When curved, the birefringence variation is always subperpendicular to the fibre long axis at any given location, as observed in Fig. $3 \mathrm{C}$ with more subtle birefringence variation in Fig. 3B. Secondly, a characteristic feature is the occurrence of series of subgrains parallel to the fibre long axis, as schematically represented in Fig. 9C. In thin sections parallel to the fold profile (i.e. the XZ-plane of displacement) the subgrains are elongated, but in $X Y$ sections subgrains form a pattern of rhombs. Subgrains therefore appear as elongated prisms with their two long axes parallel to the fold profiles (see Fig. 9C for 3D interpretational sketch). Thirdly, many secondary fluid inclusion planes (FIPs) lie parallel to the subgrains, i.e. parallel to the fibre long axis. Other FIPs are perpendicular to the fibre long axis, always restricted to a given fibre, either continuous across or stopping halfway through the fibre (inset in Fig. 9A). The latter can be classified as pseudo-secondary FIPs, although it is difficult to state with certainty whether they are growth or deformation related based on purely petrographic observations (Van den Kerkhof and Hein, 2001). Fourthly, zoned variations in cathodoluminescence tone lie parallel to the fibre long axis, in some cases corresponding to subgrain boundaries and/or FIPs. However, in both cases, these features are also found without a clear relation to each other, hence a genetic link is not necessarily indicated. Finally, relatively little twinning occurs in the folded veins and no differences could be observed in density of twinning between inner and outer fold arcs or fold limbs and hinges. Some deformation twinning thus seems to have occurred prior to folding, as clearly shown by curved twinning in dolomite type I fibres.

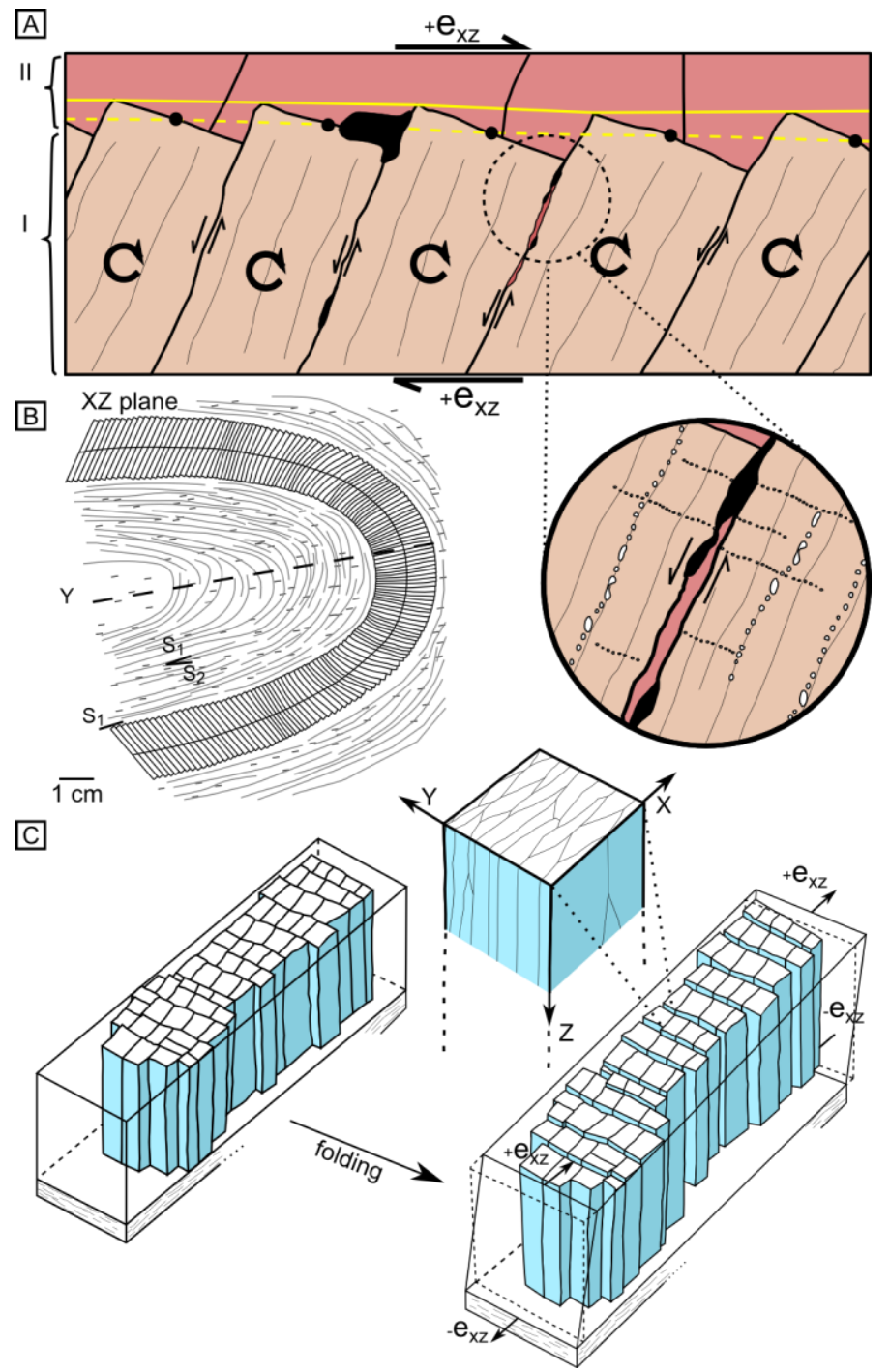

Fig. 9. (A) Schematic overview of bookshelf rotation, with parallel microfaulting along grain boundaries and concomitant rotation of fibres (Mandl, 1987). Illustrated microstructural observations are dull red luminescent dolomite and sulphides precipitating later along grain boundaries, two orthogonal fluid inclusion planes and formation of subgrains parallel to the long axis of the dolomite fibres. (B) Displacement reference framework used in this paper and schematic overview of internal fabric of folded type I veins in the XZ plane of displacement, perpendicular to the fold hinge line. (C) 3D sketch of collective rotation of dolomite fibres, with layer-parallel simple shear deformation. Inset shows elongated subgrains parallel to the long axis of the dolomite fibres.

\subsection{Microfabric in type II veins}

Growth morphologies in type II veins often show a particular pattern. Firstly, the contact between type I and II veins is often concomitant with a change in growth morphology, from fibrous to blocky grains. Type II overgrowths generally retain the type I fibre width only for a couple of tens of micrometers (50- $100 \mu \mathrm{m}$; Figs. 3B, 4 and 5), subsequently leading to a sub- to euhedral blocky vein gangue dolomite. Quite often, extreme amounts of grain size increase are observed $(>10$ times), with blocky crystals that can laterally span multiple type I fibres (e.g. Fig. 4A). Secondly, many veins subsequently 
show transitions in growth morphology from the euhedral blocky type II dolomite towards strongly curved elongateblocky or sometimes fibrous dolomite growth morphologies near the final growth surface in the veins (Figs. 3, 4 and 5). These morphologies are related to slickenfibres and slickenline lineations in the fold limbs. An opposite trend in growth morphologies was not observed in this study. Where type II dolomite becomes elongate-blocky or fibrous, grains reveal a clear change in growth direction through curvature of dolomite fibres gradually changing in orientation from initially perpendicular up to parallelism with the vein wall (Fig. 5). These curved crystals lack intracrystalline deformation features. In most cases, the curvature attitude in the type II overgrowths is opposite on both sides of a given limb, as demonstrated in Figs. 3B and 5.

The final growth surfaces on the vein walls are often lined with mica and chlorite slickenlines or slickenfibre morphologies or by dolomite slickenfibres (Figs. 4 and 5). This occurs on both type I and II veins. The mica or chlorite slickenfibres commonly reveal identical birefringence in all grains along a slickenfibre surface, indicating a strong preferred orientation. The curvature of elongate-blocky to fibrous type II dolomite and the nature of slickenfibre steps generally indicate reverse slip shear sense on opposite sides of folds.

The type I - II contact often reveals intense and localised deformation features in dolomite. Dolomite grains generally show an increase in deformation twinning, undulose extinction, subgrains and fracturing near the I - II contact, both at the top of type I fibres and during first growth of type II dolomite (Fig. 4). Fig. 6B shows localised deformation twinning at the top of type I dolomite fibres that abruptly ends at the contact between type I and II dolomite whereas other generations of deformation twins crosscut this surface and clearly postdate formation of type II dolomite. Additionally, abundant twinning is seen near the transition of type I and II dolomite but at a certain point this twinning disappears in the type II overgrowths with a concomitant change in growth morphology towards strongly curved growth (Fig. 4). The curvature of dolomite grains or shear sense at type I - II contacts can either show similar (Fig. 6A) or opposite (Figs. 3B and 5) shear sense relative to bookshelf rotation of type I fibres.

\section{Kinematic interpretation}

\subsection{Internal strain distribution in the folded single layer- flexural flow folding}

Microstructures in the fold hinges show a remarkable absence of strain accumulation, with no evidence for large-scale pressure solution, twinning or other intracrystalline deformation features. There is also no microstructural evidence for any strain gradient between the inner and outer vein wall at the hinges. Conversely, deformation in the limbs is higher by intracrystalline bending and intergranular bookshelf rotation of type I dolomite fibres. In addition, bookshelf rotation is always with a reverse shear sense relative to the initially orthogonal orientation on opposite sides of the fold hinges. Shear deformation is therefore localised in the limbs. Hence, all these observations point to a strain field that complies with that of flexural flow folding, concentrating strain in fold limbs and accommodating little or no strain in fold hinge zones, as opposed to folding by tangentiallongitudinal strain.

\subsection{Progressive fold amplification}

The variation in fold amplitude across $2^{\text {nd }}$ and $3^{\text {rd }}$ order folds (Fig. 2) agrees with parasitic fold development in a single progressive deformation history of a multilayer sequence, yielding the largest amplitudes when layer inclination is parallel to the main contraction direction (Treagus and Fletcher, 2009; Hudleston and Treagus, 2010; Hobbs et al., 2011). The observed extension structures (i.e. pinch-and-swell geometries; boudins) in steeply dipping to slightly overturned limbs most probably relate to stretching of fold limbs during progressive closure of $2^{\text {nd }}$ and $3^{\text {rd }}$ order folds to isoclinal and slightly overturned folds, with the veins acting as material lines rotating from the shortening towards the extension field during progressive deformation (Passchier and Trouw, 2005).

It is clear that during progressive folding, type I veins behaved as competent layers in an incompetent matrix, leading to buckling and low angle thrusting. Thickness variation along the folds, the characteristics of the type I to type II transition, the inferred growth direction of type II overgrowths, and the progressive changes in growth morphology of type II veins, all suggest that type II veins grew synkinematically during progressive $2^{\text {nd }}$ and $3^{\text {rd }}$ order folding.

Numerical modelling has inferred that progressive fold evolution of a single layer comprises a number of stages: (1) initial layer-parallel shortening, (2) the nucleation of a buckling instability, (3) a fold amplification and (4) pure shear deformation due to locking up of the folds (Schmalholz and Podladchikov, 2000, 2001; Schmalholz, 2006; Hudleston and Treagus, 2010). These stages can be recognized in the microstructural evolution of the type I and type II dolomite veins.

\subsubsection{Early bedding-parallel shear}

Where present, the contact between type I and II veins localises shear strain, with increased twinning and subgrain development, both at the top of type I veins as well as during first growth of type II veins. Often the first tens of $\mu \mathrm{m}$ of crystal growth of type II veins show highly deformed and curved crystals, a large grain size reduction and abundant deformation twinning and other intracrystalline deformation features (Fig. 4). These observations all indicate lowdisplacement bedding-parallel shear strain. The shear sense of the type I-II contact does not change across fold profiles. This indicates that bedding-parallel shearing must have occurred during initial layer-parallel shortening, both before and during first growth of the type II veins, before any significant buckling and fold amplification took place.

\subsubsection{A stage of high transient permeability}

In almost all type II veins, an important stage of blocky euhedral growth follows the early shear. Starting from the type I-II contact towards the host-rock vein wall, type II veins often show a change from small grain sizes and fibrous morphologies, rapidly increasing in grain size towards more elongate-blocky and ultimately euhedral blocky grains (Figs. $3 \mathrm{~A}$ and 4). Consequently, many type II veins are dominated by euhedral blocky growth morphologies in dolomite and quartz 
selvages, with grains that are devoid of solid inclusions or dust rims and that reveal well-developed growth facets.

These observations point to intense growth competition starting from the initial growth surface (the type I - type II contact) and are indicative for a sustained vein opening, inferring a vein-wall separation rate exceeding crystal growth. Minerals with anisotropy in crystal growth vectors, such as dolomite (Dickson, 1993), can reveal growth competition by widening and occlusion of crystals when growing unimpeded into open cavities. This indicates the general growth direction - but not necessarily the exact orientation. The resulting type of growth morphology mainly depends on the opening rate of veins relative to the growth speed of the gangue minerals and the smoothness of vein walls (Urai et al., 1991; Hilgers et al., 2001; Oliver and Bons, 2001; Nollet et al., 2006, 2009). Therefore, growth of gangue minerals in type II veins started at the onset of or even before bookshelf rotation of the type I fibres due to flexural flow folding and continued with open cavity growth during progressive buckling and fold amplification.

Occasionally, several inclusion trials of Cu-Co sulphides and micas lie parallel to the vein walls and the type I - type II contact. In addition, multiple euhedral blocky dolomite generations are recognised under cold cathodoluminescence, each generation cutting off existing deformation features or growth facets of previous dolomite stages (Fig. 4; cf. Barker et al., 2006). These observations indicate multiple opening and closing episodes.

The highest volumes of $\mathrm{Cu}$-Co sulphides are associated with this euhedral blocky dolomite stage in type II veins, whereas $\mathrm{Cu}$-Co sulphides are absent in type I veins and minor in early and late shearing stages in the folded single-layers. This means that a large portion of $\mathrm{Cu}$-Co sulphide mineralisation at Nkana precipitated after buckling instability was already created and thus primarily occurred during the fold amplification stage, creating transient permeabilities necessary for deposition of large quantities of $\mathrm{Cu}-\mathrm{Co}$ sulphides (cf. Evans and Fischer, 2012).

\subsubsection{Curved fibres and flexural slip components towards fold closure}

Many type II veins subsequently reveal a change from the euhedral blocky dolomite towards strongly curved elongateblocky, sometimes fibrous dolomite slickenfibre growth morphologies with slickenlines on the vein walls. Although caution should be taken when interpreting kinematics from curved fibrous veins (Williams and Urai, 1989; Urai et al., 1991; Hilgers et al., 2001; Bons et al., 2012), the fibres are undeformed and show a progressive curvature from orthogonal up to parallelism with the vein walls and $S_{1}$ cleavage, ultimately forming slickenfibre geometries. No twinning or subgrains are seen in the curved dolomite. In addition, there is an absence of jagged grain boundaries or briquette structures typical for ataxial veins, where fracturing is randomly distributed within the vein (Hilgers and Urai, 2002). Solid inclusion trails can directly track the opening direction of a vein (cf. de Roo and Weber, 1992; Koehn and Passchier, 2000), but these were not found in the type II veins. Considering these lines of evidence, these type II fibres have grown during progressive folding, with the direction of curvature reflecting to a high degree the opening direction in the fold framework.

This final growth stage in type II veins is consistent with that expected in flexural-slip folding, as evidenced from a reverse shear sense in slickenfibres on opposite sides of folds, a subparallelism of slickenfibre steps with the local fold hinge lines and slickenline lineations perpendicular to these fold hinge lines. Therefore, a component of flexural slip acted in some veins complementary to the initial flexural flow in the accommodation of the overall strain during folding. Where fold limbs are steep to sub-vertical, shear zones are formed at low angle to bedding, yielding duplex structures of type I veins. These duplexes are typical for flexural slip along bedding planes (Tanner, 1992). Hence, in some folds simple shear strain may be homogeneously distributed through the layer in flexural flow folds. In others it may be more inhomogeneously distributed with slip localised on the layer boundary (flexural slip) rather than distributed within the layer itself (Ramsay, 1967 p392; Tanner, 1989). The return from euhedral blocky to fibrous and shear-related growth morphologies, indicates that this flexural slip stage represents the onset of locking up of the folds (cf. Hudleston and Treagus, 2010), especially in multilayer sequences where chevron-type folding is common.

\subsection{Effects of multilayer folding}

All multilayers show extremely high amplitude harmonic folding, often leading to chevron-type folds having amplitudes two to three times as large as those in single-layer folds of similar thickness. Such amplitude differences can be understood as an intrinsic effect of multilayer folding, where growth rates of folds during fold amplification are higher than those in single layers (Frehner and Schmalholz, 2006; Schmid and Podladchikov, 2006; Treagus and Fletcher, 2009). In addition, folds in an anisotropic matrix propagate well into the matrix and therefore do not die out as quickly away from the stiff layer as in an isotropic matrix (Kocher et al., 2006, 2008; Hudleston and Treagus, 2010).

As the spacing between veins decreases, multilayer fold trains show an increase in amplitude and a change in multilayer behaviour. Some multilayers at Nkana show extremely high amplitude chevron type folding. In this case, spacing of the veins is small, with the volume of matrix being close to the volume of veins. Therefore, these folded vein sequences are interpreted as 'true multilayers' (cf. Schmid and Podladchikov, 2006; Hudleston and Treagus, 2010). However, more frequently, folded stacks of type I veins yield disharmonic to polyharmonic folds, with a larger spacing between folded veins, although still relatively closely spaced (Fig. 22D). These veins can be considered as ranging more towards independent single layer folds (cf. Schmid and Podladchikov, 2006).

There is a distinct difference in the amount and type of accommodation structures in type II veins between singlelayer folds and true multilayer folds. The most intense thickness variations in type II veins are observed in the true multilayer sequences in both syn- and antiformal structures, creating euhedral blocky dolomite, quartz and coarse grained sulphides, which can be interpreted as open cavity growth in dilatational sites, i.e. saddle reefs. The observed slip along bedding planes and curved fibre growth are typical of flexural 
slip in a multilayer chevron-type fold model, which creates potential for dilatational sites in fold hinges (Ramsay, 1974; Hodgson, 1989; Cox et al., 1991; Forde and Bell, 1994; Windh, 1995; Couples et al., 1998). In the case of dis- to polyharmonically folded veins, a similar interpretation can be made, with more irregularly localised creation of dilatational sites.

\subsection{Later deformation of folded type I and type I/ veins}

In high strain areas at Nkana, disjunctive $\mathrm{S}_{2}$-cleavage planes crosscut folded type I veins and also type II veins. Many of these cleavage planes are very strongly mineralised by sulphides, quartz, dolomite and micas. This observation and the inconsistent and contrasting displacements of folded veins along one disjunctive cleavage plane (Fig. 7A) indicate diffusion mass transfer processes during progressive homogeneous shortening and serve to distinguish these apparent displacements from true shear displacements (Blenkinsop, 2000; Twiss and Moores, 2007).

Multiple wavelengths in folds must have been dissolved in order to accommodate the observed apparent displacement, as illustrated in Fig. 7, which would point to very significant homogeneous shortening with extremely intense diffusion mass transfer processes. Conversely, many veins of dolomite and quartz occur along $\mathrm{S}_{2}$-cleavage planes, often showing slickenfibre growth morphologies with microstructures indicative of growth during shearing (cf. Koehn and Passchier, 2000). Therefore, it cannot be excluded that significant shearing along $\mathrm{S}_{2}$ cleavage planes took place, besides dissolution. This could in some cases help to explain the large apparent displacements and the precipitation of authigenic quartz and dolomite along some of the $S_{2}$ cleavage planes. In general, it is quite difficult to determine how much shear strain was accumulated across foliation planes by diffusive mass transfer and how much through simple shearing (Twiss and Moores, 2007).

Some evidence is present to indicate that the development of this disjunctive cleavage is post-kinematic to the $4^{\text {th }}$ order folding and will not have influenced the earlier stages of the folding of these veins. Firstly, the diffusion mass transfer process also affects veins that show type II vein overgrowths and veins crosscutting already folded type I veins, with abrupt interruption of type II dolomite near the cleavage planes, as visible in Fig. 7. It is difficult to envisage simultaneous development of open cavity growth of dolomite in type II veins and concomitant compaction related dissolution. Secondly, the geometry of the contact between type I veins and the cleavage and the amount of shortening are not compatible with a bulk of shortening to have occurred prior to or at the onset of folding. Thirdly, the disjunctive cleavage affects only those folds with the highest strain and is not present in lower-strain areas, although similar fold geometries are found in both cases.

\subsection{Summary of kinematic interpretation}

The internal strain distribution in type I veins conforms to flexural flow folding. The deformation microstructures and growth morphologies in type I and II veins can be correlated to different stages during progressive folding of the veins. Ultimately, flexural slip folding is interpreted to occur during fold lock-up. The close spacing of some of the veins in multilayer systems has led to extreme fold amplification with high amplitude chevron-type folding. Significant later homogeneous flattening has affected the veins, as evidenced by a disjunctive $S_{2}$ cleavage.

\section{Dip-isogon analysis}

A dip-isogon analysis was carried out on fold profiles of folded type I veins (cf. Ramsay, 1967). Such an analysis gives a functional description of the folded layer geometry by plotting the variation of the normalised orthogonal thickness, $t=t_{0} / t_{\alpha}$, with respect to the layer inclination, $\alpha$. Here, $t_{\alpha}$ is the orthogonal thickness at layer inclination $\alpha$ and $t_{0}$ the orthogonal thickness at the hinge. Many of the detailed analyses and measurements are carried out on 4 well oriented, large $(50 \times 70 \mathrm{~mm})$ thin sections, cut perpendicular to the local fold hinge line, of representative folded type I veins (Fig. 8). The dip-isogon analysis shows that folded type I veins belong to class $1 \mathrm{C}$, close to class $1 \mathrm{~B}$ (Fig. 10), with dip isogons converging towards the inner hinge.

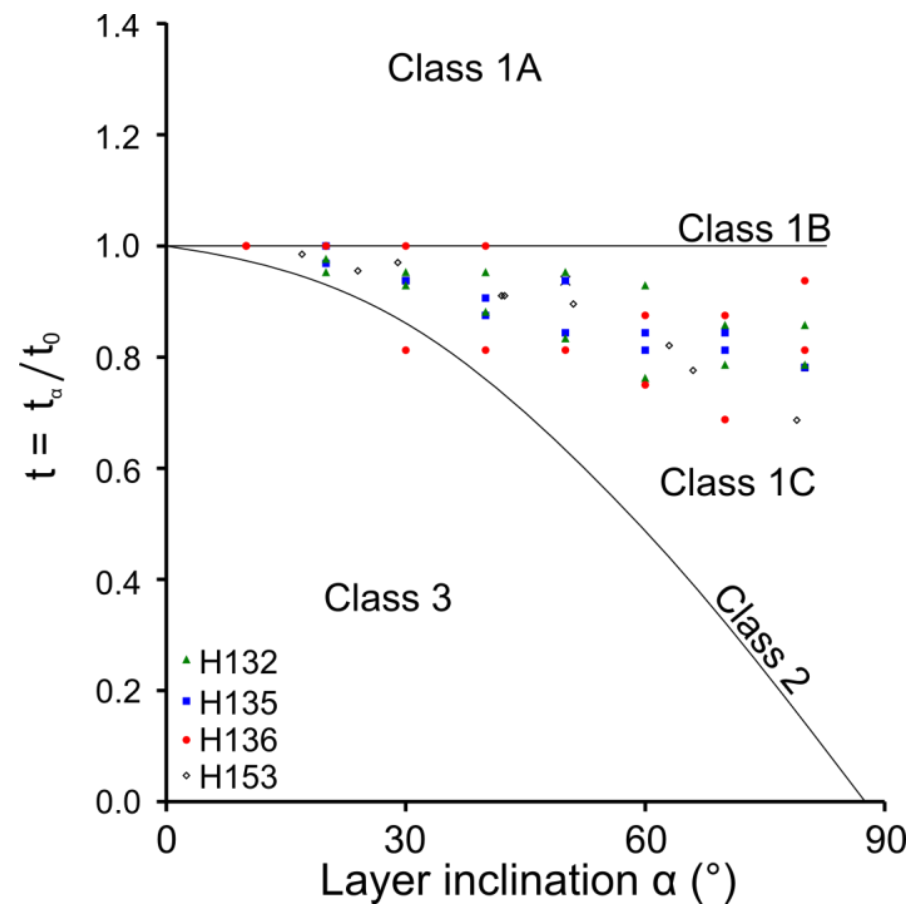

Fig. 10. Dip-isogon analysis of normalised orthogonal thickness $\left(t=t_{\alpha} / t_{0}\right)$ variation on thin sections of fold profiles of selected folded type I veins (see Fig. 8).

There are clear indications for homogeneous flattening of the folds, as evidenced by contrasting apparent shear movements of folded type I veins along disjunctive $S_{2}$ cleavage planes. When parallel folds of class $1 \mathrm{~B}$ are subjected to homogeneous flattening, i.e. pure shear, these can be transformed to class 1C folds (Ramsay, 1962; Mukhopadhyay, 1965; Lisle, 1992; Zagorčev, 1993; Srivastava and Shah, 2006). To estimate the amount of two-dimensional strain during homogeneous flattening, a reconstruction of the strain ellipsoids of the entire folds is performed. This reconstruction is based on the isogon rosette method of Srivastava \& Shah (2008), by plotting dip isogons with their point of intersection as a common midpoint. The method assumes that flattening occurs completely posterior and not concomitant to the buckling stage. This criterion is met, given that disjunctive cleavage development is interpreted to have occurred post-kinematic to the $4^{\text {th }}$ order folding. 
Resulting strain ellipsoids are shown in Fig. 11. The inferred strain ratio of the strain ellipsoids, $R_{S}$, for sample $H 136$ is 1.15 and for the other 3 samples $R_{S}=1.33$. The obtained strain ellipsoids for all four folds have their major principal axes at a very small angle with the axial planar $S_{2}$ cleavage. As the attitude of the axial planar $S_{2}$ cleavage was used as a base for defining the layer inclination across the folds, we can infer that homogeneous flattening of the folds occurred perpendicular to $S_{2}$, and is thus kinematically linked with the development of this late cleavage fabric.
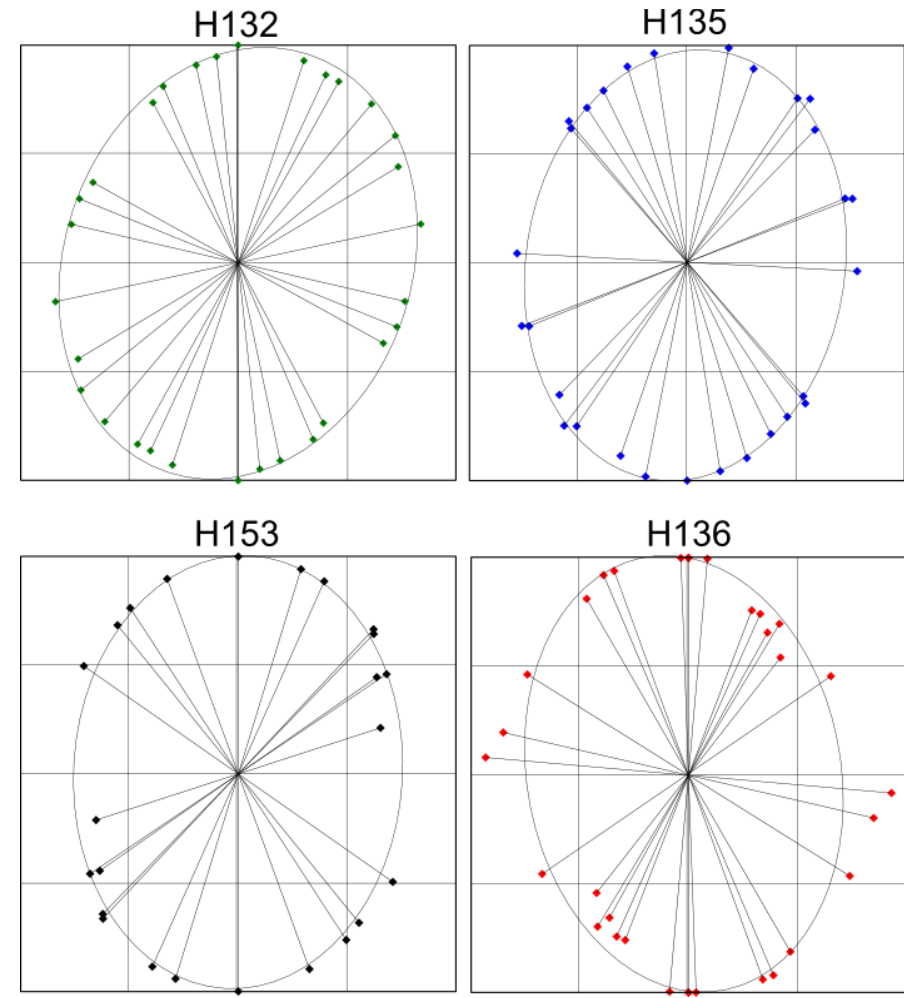

Fig. 11. Strain ellipsoids for the four folded veins (see Fig. 8), reconstructed by taking dip isogons across folds without changing their angles and then plotting them with their point of intersection as the common midpoint, following the method in Srivastava and Shah (2008). The vertical lines are parallel to local $S_{2}$ cleavages.

Subsequently, we can reconstruct the fold geometries prior to homogeneous flattening using the strain ellipsoids and deduced $R_{s}$ for the four folds in Fig. 11. We calculate the initial angles of the layer inclination, $\alpha^{\prime}$ and the smallest angle between $t^{\prime}{ }_{\alpha}$ and the $Y Z$ plane of the strain ellipsoid, $\varphi^{\prime}$ (for method see Fig. A.1 and Appendix A). Using these angles, we then calculate the restored normalised orthogonal thickness $t^{\prime}$ $=\mathrm{t}^{\prime}{ }_{\alpha} / \mathrm{t}_{0}$, deduced in Appendix $\mathrm{A}$, as:

$$
\frac{\mathrm{t}_{\alpha}^{\prime}}{\mathrm{t}_{0}}=\frac{\sin \varphi}{\sin \varphi} \frac{\mathrm{t}_{\alpha}}{\mathrm{t}_{0}} \frac{1}{\mathrm{R}_{\mathrm{S}}} .
$$

Fig. 12 shows the variation of the restored normalised orthogonal thickness for the four fold profiles of Fig. 8. This reconstruction clearly shows that when homogeneous flattening is taken into account, the original folds are parallel folds (class 1B).

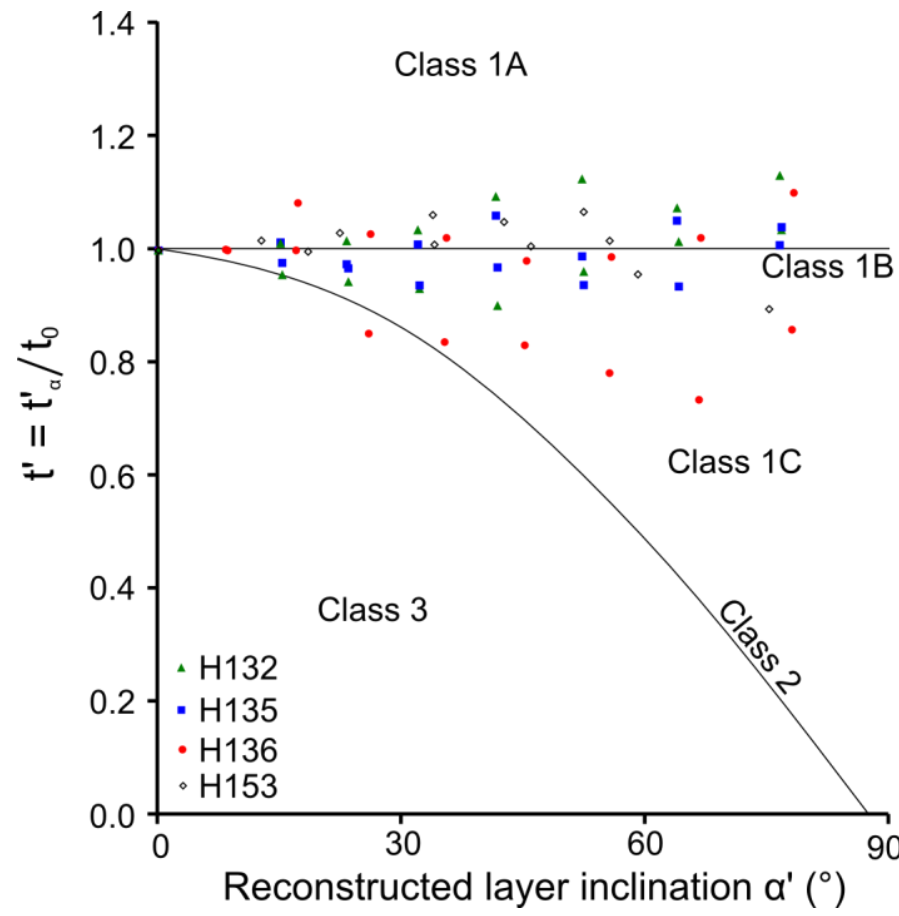

Fig. 12. (A) Reconstruction of normalised orthogonal thickness, $t^{\prime}=t^{\prime}{ }_{a} / t_{0}$ of dip isogons across the folds for the four selected folds (Fig. 8), before homogeneous flattening, using the inferred strain ratios of Fig. 11.

\section{Quantification of strain using dolomite fibres as planar markers}

The strain pattern within a fold cannot be deduced from fold shape alone and planar markers offer a great addition to quantitatively study strain patterns within a fold (Hudleston and Lan, 1993; Lisle, 1999; Bastida et al., 2005; Bobillo-Ares et al., 2009). Only in flexural flow do initially orthogonal markers deviate from orthogonal position in parallel folds, whereas in pure tangential-longitudinal strain, markers originally orthogonal to the neutral surface of the layer remain so after deformation (Hudleston and Holst, 1984; Hudleston and Lan, 1993). Petrographic analysis and macroscopic observation of relatively undeformed type I veins reveal that the dolomite fibres were initially orthogonal to the vein walls. Because of the consistency in this observation, we can utilise the fibre attitude as a marker to quantify strain patterns and the intensity of the mechanisms at play during folding.

Deformation at a given position across a layer folded by flexural flow is a superposition of homogeneous layer-parallel simple shear, $\mathbf{F}_{\mathbf{S}}$, and a rotation, $\mathbf{R}$ (Ramsay, 1967; Bastida et al., 2003). The deformation gradient tensor for flexural flow, $\mathbf{F}_{\mathrm{FF}}$, is then

$\mathbf{F}_{\mathbf{F F}}=\mathbf{R F}_{\mathbf{S}}=\left[\begin{array}{cc}\cos \gamma & -\sin \gamma \\ \sin \gamma & \cos \gamma\end{array}\right]\left[\begin{array}{ll}1 & \gamma \\ 0 & 1\end{array}\right]$

with $\gamma$ the layer-parallel component of the finite shear strain (Bastida et al., 2003). Therefore, by quantifying the shear $\gamma$, we can determine $\mathbf{F}_{\mathbf{S}}$, and thus the strain distribution across the folds. In simple shear, lines at angle $\beta_{i}{ }^{\prime}$ to the simple shear plane are sheared to $\beta^{\prime}$ and these two angles are related to each other via

$\cot \beta^{\prime}=\cot {\beta^{\prime}}_{i}+\tan \psi=\cot \beta_{i}^{\prime}+\gamma$, with $\gamma=\tan \psi$ 
(Ramsay, 1967; Ragan, 2009). In our case, dolomite fibres were initially orthogonal to bedding, i.e. $\beta^{\prime}{ }_{i}=\pi / 2$, and therefore $\cot \beta_{i}^{\prime}=\cot \pi / 2+\gamma=\gamma$ (Fig. 13).
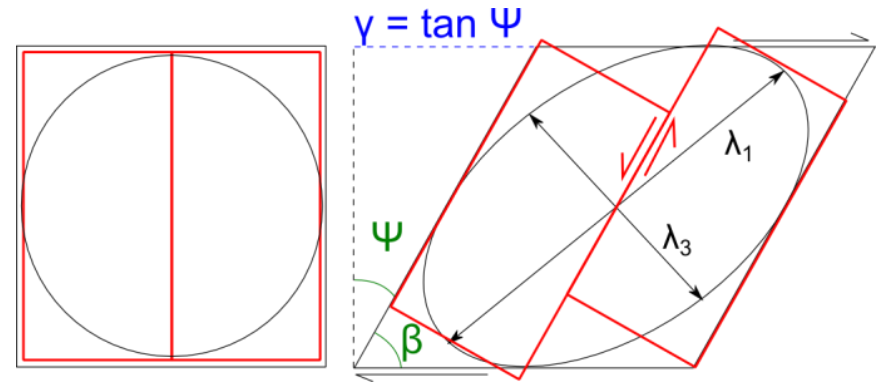

Fig. 13. Geometrical basis behind the strain ellipsoid reconstruction. Initially orthogonal fibres (in red) are deformed by bookshelf rotation, up to an obliquity angle $b^{\prime}$ (Bobillo-Ares et al., 2009). From this obliquity angle, parameters of the deformed strain ellipsoid are calculated, namely the angular shear $\psi$ and shear gamma $\gamma$, as well as relative magnitudes $\lambda_{1,3}$ of the principal strain axes.

Consequently, from $\gamma$ the parameters of the strain ellipsoid under simple shear deformation can also be calculated (Ramsay, 1967). The lengths of the principal axes of a strain ellipse in simple shear are $1+e_{1}=\lambda_{1}^{0.5}$ and $1+e_{3}=\lambda_{3}^{0.5}$ with $\lambda_{1,3}$ given by

$\lambda_{1,3}=\frac{\gamma^{2}+2 \pm \sqrt{\left(\gamma^{2}+2\right)^{2}-4}}{2}$.

Accordingly, the strain ratio $R_{S}$ at a given point, is

$\mathrm{R}_{\mathrm{S}}=\frac{1+\mathrm{e}_{1}}{1+\mathrm{e}_{3}}=\frac{\sqrt{\lambda_{1}}}{\sqrt{\lambda_{3}}}$

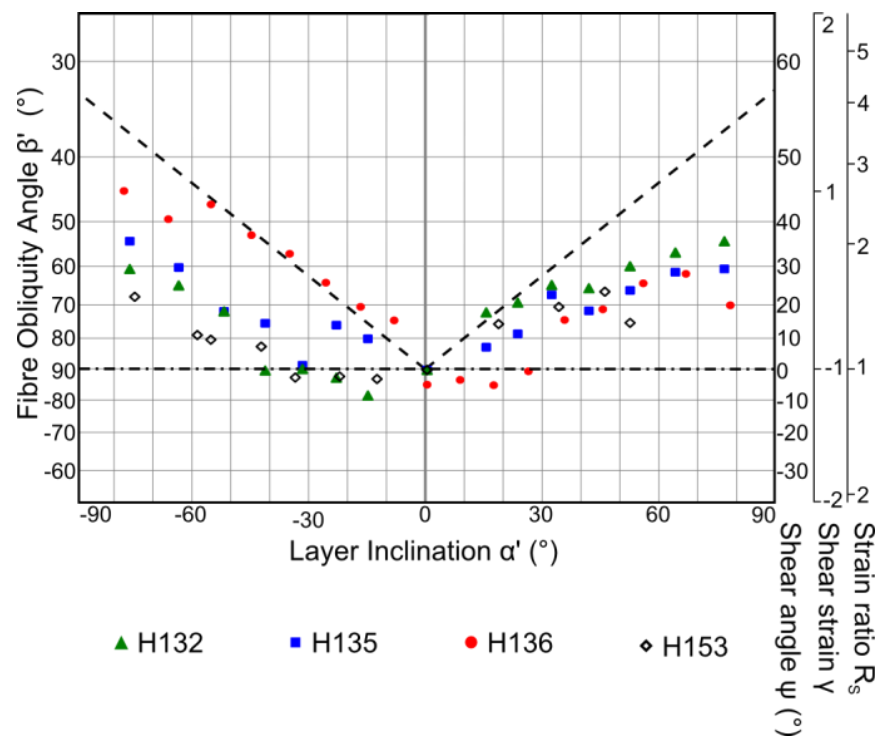

Fig. 14. Layer inclination $\alpha^{\prime}$ and obliquity angle of dolomite fibres, $b^{\prime}$, in selected type I veins, corrected for homogeneous flattening. The associated shear strain angle $\psi$, total shear strain $\gamma$ and strain ratio $R_{S}$ of the principal strain axes are calculated using Eq. (2) to Eq. (5). Theoretical relationships are plotted for initially orthogonal passive markers $(B=\pi / 2)$ under flexural flow and tangential-longitudinal strain folding, with a dashed and dashed-dotted line, respectively (cf. Ramsay, 1967; Bobillo-Ares et al., 2009).

Measurements were carried out on the same veins used in the dip-isogon analysis. Angles of layer inclination $\alpha$ and fibre obliquity angle $\beta$ were corrected for the homogeneous flattening using Eq. (A1) in Appendix A. Subsequently, Eq. (3) to Eq. (5) were applied to calculate $\psi, \gamma$ and $R_{s}$. Fig. 14 shows the variation of the restored obliquity angle $\beta^{\prime}$ of the fibres for the four folds (cf. Bobillo-Ares et al., 2009) and the calculated shear angle $\psi$, finite shear strain $\gamma$ and strain ratio $R_{S}$ relative to the layer inclination $\alpha^{\prime}$. These results reveals increasingly higher $\psi, \gamma$ and $R_{S}$ towards the fold limbs, up to simple shear strains of $\gamma=0.6$ to 0.7 and strain ratios of $R_{S}=2$. As expected, the simple shear strain is completely absent in the fold hinges, with $\gamma=\alpha^{\prime}=0$.

Results deviate somewhat from the theoretical strain curve for an initially orthogonal marker under pure flexural flow but deviate more strongly from that of tangential-longitudinal strain (Fig. 14). This indicates that the folding mechanism is probably a combination of flexural flow and a minor component of tangential-longitudinal strain (Bobillo-Ares et al., 2009). However, this deviation can also be interpreted as due to fibres not being passive flow markers, but rather dynamically deforming active markers (Fossen, 2010). For this reason, the reconstruction is not an exact solution but a good first-order approximation.

\section{Viscosity contrast and bulk strain}

Many methods are used to estimate viscosity contrasts in folded single layers. One such classical method is the arc length method, measuring the arc length relative to the thickness of a folded layer (Bastida et al., 2005; Hudleston and Treagus, 2010). Others have used thickness versus wavelength of folded veins as an indicator of viscosity contrast or kinematic modelling, but these methods have yielded inconsistently reliable predictions for fold-related deformation (Evans and Fischer, 2012).

Here, the strain contour method proposed by Schmalholz \& Podladchikov (2001) was used. This analysis uses wavelengthnormalised $(\lambda)$ amplitude $(A)$ versus thickness $(H)$ graphs to constrain (1) the viscosity contrast and (2) bulk strain accommodated from a point at which the nucleation amplitude is reached during initial buckling development (Schmalholz and Podladchikov, 2001; Llorens et al., 2013). The method does not take into account layer-parallel shortening before the folding stage. Results from the strain contour map can give a first order approximation of the viscosity contrast, as the exact folding mechanism at a given viscosity contrast is also dependant on the stress exponent (Schmalholz and Podladchikov, 2001; Llorens et al., 2013). An important assumption of the method is that the fold initiated at the dominant buckling wavelength. If it did not, the measure of bulk strain measure is an underestimation (Schmalholz and Podladchikov, 2001; Hudleston and Treagus, 2010).

Measurements were carried out in the field on relatively isolated and independently folded type I veins in several crosscuts in the Nkana mines (e.g. Fig. 2C). The thickness, $\mathrm{H}$, in the strain contour map was always measured as the orthogonal thickness in the fold hinge of the type I veins. The results in Fig. 15 demonstrate that the inferred bulk strain starting from the situation at the nucleation amplitude is generally over $65 \%$. In addition, the viscosity contrast between type I veins and the host rock matrix is always $\mu \mathrm{l} / \mu \mathrm{m}>50$, although a large variability exists in obtained values. 


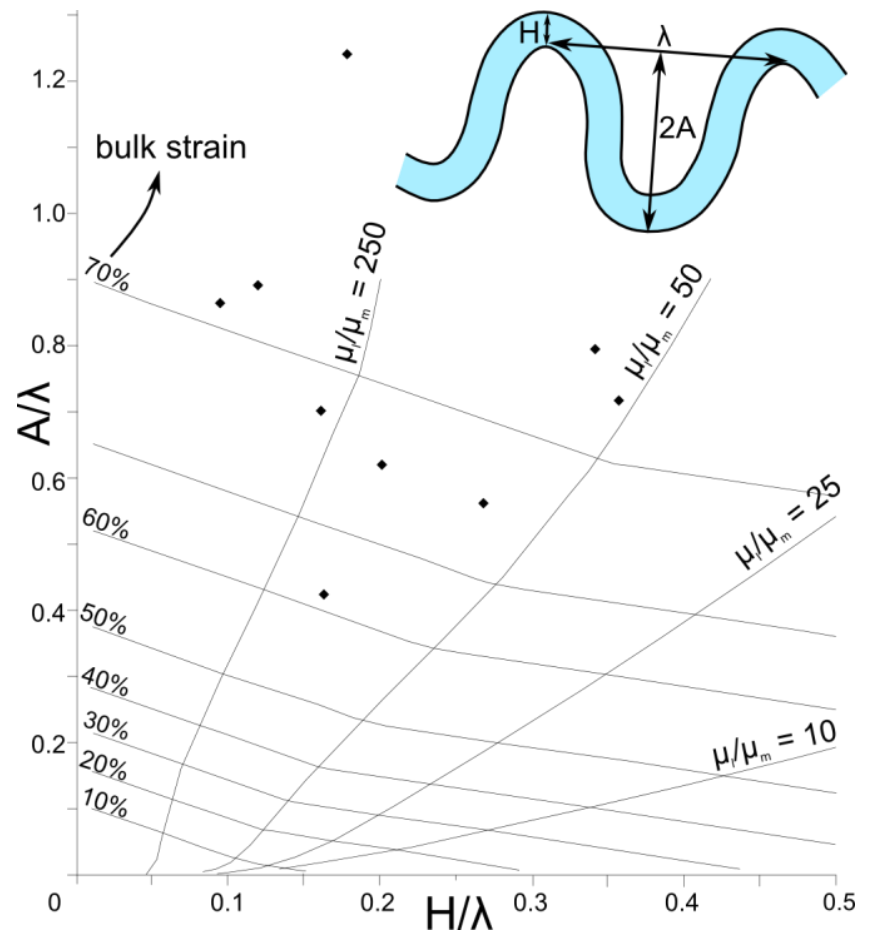

Fig. 15. Strain contour curve for single-layer folds of type I veins showing amplitude (A) versus layer thickness (H) normalised over wavelength ( $\lambda$; cf. Schmalholz and Podladchikov, 2001).

\section{Discussion}

\subsection{Effect of anisotropy on folding}

It is clear from the results of this study that the type I veins acted as highly viscous layers in an incompetent matrix, and not as semi-passive markers. Why then do these folded type I veins approximate the strain pattern and geometry of flexural flow folds as opposed to tangential-longitudinal strain, the expected fold mechanism?

Flexural flow folding is theoretically often envisaged as the folding of a deck of cards or as a stack of layers with infinitesimally small thicknesses. These numerous layers then intrinsically lead to a high anisotropy parallel to the plane of simple shear as an aggregate response, by which the folding can approach the flexural flow regime. Several studies have indeed demonstrated an important effect of layer and matrix anisotropy on folding (Treagus, 2003; Kocher et al., 2006, 2008; Toimil and Griera, 2007). As such, anisotropy in the viscous matrix, within single-layers or as an aggregate multilayer response, strongly influences the occurrence of the buckling instability and also correlates positively with fold amplitude amplification rate.

However, such anisotropy parallel to $S_{1}$ is clearly not observed in the type I veins. As opposed to the deck of cards model, no thin alternating layers of different viscosity exist within the fibrous type I veins. On the contrary, the main anisotropy in the veins is the anisotropy in shear strength of the fibres, leading to a transversely isotropic fabric. The essentially cohesionless grain boundary surfaces between the individual fibres were activated as shear planes, through which strain could be accommodated. If the folded layers would have consisted of homogeneous dolomite instead of fibrous dolomite, the lack of anisotropy and homogeneity of internal fabrics would probably have caused the internal strain distribution in the folds to approach tangential-longitudinal strain.

Microstructural observations revealed that simple shear deformation in the limbs, accommodating flexural flow, is taken up by two main mechanisms, namely by a combination of intracrystalline deformation, i.e. crystallographic bending of the fibres and intergranular deformation, i.e. bookshelf rotation. Therefore, the total shear angle $\psi_{\mathrm{t}}$ is the sum of the shear angles for bookshelf rotation, $\psi_{\mathrm{br}}$, and bending of fibres, $\psi_{\text {bre, so that }} \psi_{\mathrm{t}}=\psi_{\mathrm{be}}+\psi_{\mathrm{br}}$. The angles are geometrically defined in Fig. 3C. Maximum observed shear angles by bending alone are always $\psi_{\mathrm{be}}<15^{\circ}$ for a given fibre along its total length, yielding $\gamma_{\text {be }}=0.27$. In contrast, total shear strain relative to the initial layer-perpendicular position for this example is $\psi_{\mathrm{t}}=42^{\circ}$, yielding $\gamma_{\mathrm{t}}=0.9$. The amount of intracrystalline shear strain of the dolomite relative to the total shear strain including intergranular bookshelf rotation deformation, is therefore $\psi_{\text {be }} / \psi_{\text {br }} \leq 0.27 / 0.9 \leq 0.3$. Most of the shear strain is therefore taken up by the intergranular bookshelf rotation of the fibres.

\subsection{Variation of strain between fold limbs}

Some authors note that in flexural flow, no variation in strain occurs across the folded layer from the inner to the outer arc (Bastida et al., 2005), whereas others have argued that the largest intensity of flexural flow is located in the centre of the layer and decreases towards the boundaries (Toimil and Griera, 2007). The last authors note that the numerical modelling of flexural flow folding by Hudleston et al. (1996) also revealed such increase in flexural-flow intensity towards the centre of competent layers. From the microstructural evidence in our study (Figs. 3B) the simple shear strain appears to be relatively homogeneously distributed from the inner and outer arc, with no real evidence of an increase in intensity of flexural flow towards the centre of the veins.

\subsection{Influence of internal fabric on strain distribution in single-layer folds}

Other studies have also investigated the relation of microstructures and internal fabrics to the folding mechanism and internal strain distribution (e.g. Zhang et al., 1993; Hudleston and Srivastava, 1997; Hippertt and Tohver, 2002). Hippertt \& Tohver (2002) studied the effect of fabrics on strain accommodation in a micaceous quartzite fold that was folded under greenschist facies metamorphic conditions. They demonstrated development of a $\mathrm{S}-\mathrm{C}$ fabric during folding and oblique shear on the S-bands within the single-layer.

Hudleston and Srivastava (1997) investigated the crystallographic fabric in a folded fibrous calcite vein, and showed an increasing intensity in twinning from the outer to the inner edge of the folded vein, with fibres remaining subperpendicular to the layer inclination. From these observations, they inferred the folding mechanism to be tangential-longitudinal strain, with important pre-existing homogeneous shortening before folding. In our case, little twinning was observed in most of the folded veins and it is clear that other deformation mechanisms accommodated the strain during folding. Dolomite exhibits high crystal-plastic strength regardless of grain size at temperatures below $700{ }^{\circ} \mathrm{C}$ (Davis et al., 2008). Opposed to this, deformation twinning in calcite occurs more easily and at lower temperatures and 
differential stresses than in dolomite (Passchier and Trouw, 2005; Davis et al., 2008). These differences in strength can explain why sliding along grain boundaries by bookshelf rotation could take place instead of intracrystalline deformation such as twinning.

From our and other studies, we can thus conclude that the internal fabric and mineralogy, and in particular vein microstructures, exhibit a first order influence on strain distribution, controlling in part the folding kinematics. The study of microstructures in folded veins can therefore provide more insight into fold kinematics and strain accommodation, when the nature of the initial pre-deformational vein fabrics is well known. This study also emphasizes the complexity of internal fabric in many veins and single layers, something that needs to be taken into account in various (numerical) models of folding.

\subsection{Enhanced permeability structures: implications for fluid flow and metallogenesis}

Much of the Cu-Co mineralisation is associated with synorogenic type II veins that are strongly related to deformation of the pre-folding type I fibrous dolomite veins, although later vein generations posterior to type II veins are also important in the metallogenetic evolution (Brems et al., 2009; Muchez et al., 2010). Without these highly competent type I veins, synorogenic type II veins and associated $\mathrm{Cu}$ sulphide mineralisation would probably not have formed in the finegrained matrix of the Copperbelt Orebody Member at Nkana South and Central. Therefore, the mere presence of type I veins must be considered important in the metallogenesis of the deposit by creating the necessary enhanced transient permeability required for fluid flow to occur in these deposits (cf. Evans and Fischer, 2012).

Several other deposits in the Central African Copperbelt contain pre-folding bedding-parallel veins with fibrous growth morphology (Mendelsohn, 1961b; Sweeney et al., 1986; Annels, 1989; Selley et al., 2005; McGowan et al., 2006; Sillitoe et al., 2010; Hitzman et al., 2012; Schuh et al., 2012; Torremans et al., 2013), although not all of these deposits reveal the exact same fine-grained carbonaceous argillite facies as in this study. Hence, if the pre-folding veins are present in these deposits, similar mechanisms could be at work. The nature of folded competent fibrous veins in finegrained sequences could potentially be used as an extra proxy in exploration in the Central African Copperbelt, because of the intrinsic link between the nature of deformation of these competent veins and large pulses of $\mathrm{Cu}-\mathrm{Co}$ mineralisation.

\section{Conclusions}

The expected strain accommodation mechanism for competent single-layer folds in an incompetent matrix is tangential-longitudinal strain. However, our study reveals an internal strain distribution diagnostic of a high contribution of flexural flow in particular bedding-parallel fibrous dolomite veins. Simple shear strain appears to be relatively homogeneously distributed from the inner and outer arc, with no evidence of increase in intensity of flexural flow towards the centre of the veins. This strain was accommodated mainly through intergranular bookshelf rotation and in minor amounts through intracrystalline bending of initially orthogonal dolomite fibres. Flexural flow folding is thus caused by a planar mechanical anisotropy initially perpendicular to the boundaries of the single-layers. Hence, from our and other studies, we can conclude that the internal vein fabric has a first-order influence on folding kinematics and strain accommodation. This study emphasizes that the complexity of internal fabric in many veins and single layers should be taken into account in various (numerical) models of folding. Moreover, type I fibrous dolomite veins show a high viscosity contrast with the shale matrix. This viscosity contrast was essential in creating transient permeability for subsequent $\mathrm{Cu}$-Co mineralising stages during the development of the type II syn-folding veins.

\section{Acknowledgements}

We thank Prof. Dr. Osbert Sikazwe and the School of Mines of the University of Zambia for logistic support. We also thank Mopani Mines Plc. for access to the research area and the geologists at Mopani for logistical assistance and many interesting discussions, in particular Wellington Mukumba, Benny Shikwe, Chanda Luwimba, George Chilufya, Stanley Chasauka, Morden Hangoma, Whiteson Silondwa, Lazarus Mwelwa, Emanuel Mwampokota, Mumba Freda and Kennedy Mpolwa. We are grateful to Jorik van Wilderode and David Debruyne for assistance during field work and stimulating discussions on the geology, metallogenesis and vein forming mechanisms. This research is financially supported by research grant OT/11/038 of the KU Leuven Bijzonder Onderzoeksfonds and FWO-Vlaanderen research grant G.0414.08N. We thank Ian Alsop for the editorial handling and Fernando Bastida and an anonymous reviewer for their comments, which helped us to clarify this paper.

\section{Appendix A}

The change in orientation of a given vector $r(x, y)$ representing any material line in an undeformed circle, towards a vector $\mathbf{r}^{\prime}\left(\mathrm{x}^{\prime}, \mathrm{y}^{\prime}\right)$ in the deformed strain ellipse can be described by:

$\tan \theta=\tan \theta^{\prime} . R_{s}$

with $\theta$ and $\theta^{\prime}$ the angle between the vector and the plane perpendicular to the shortening direction before and after shortening shear respectively (Ragan, 2009). Using Eq. (A1), we geometrically reconstruct the initial angles before homogeneous flattening of the layer inclination, $\alpha^{\prime}$, the dolomite fibre obliquity angle, $\beta^{\prime}$ and the smallest angle between $\mathrm{t}^{\prime}{ }_{\alpha}$ and the $\mathrm{YZ}$ plane of the strain ellipsoid, $\varphi^{\prime}$. These angles and their relation before and after shortening are illustrated in Fig. A.1.

From these restored angles, the normalised orthogonal length before homogeneous shortening $t^{\prime}=t^{\prime}{ }_{\alpha} / t_{0}$ is reconstructed from the relationships:

$\tan \phi^{\prime} \cdot R_{S}=\tan \phi$

and from Fig. A.1B:

$\sin \phi=\frac{\tan \phi}{t_{\alpha}}$ and $\sin \phi^{\prime}=\frac{\tan \phi^{\prime}}{t_{\alpha}^{\prime}}$.

After substituting Eq. (A3) in Eq. (A2), we come to the following relation: $\sin \phi^{\prime} \cdot t^{\prime}{ }_{\alpha} \cdot R_{S}=\sin \phi \cdot t_{\alpha}$ or for the orthogonal thickness:

$$
\frac{t_{\alpha}^{\prime}}{t_{0}}=\frac{\sin \phi}{\sin \phi^{\prime}} \frac{t_{\alpha}}{t_{0}} \frac{1}{R_{S}} .
$$




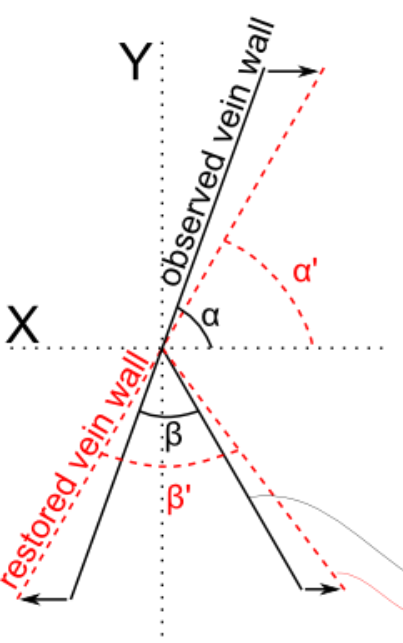

B)

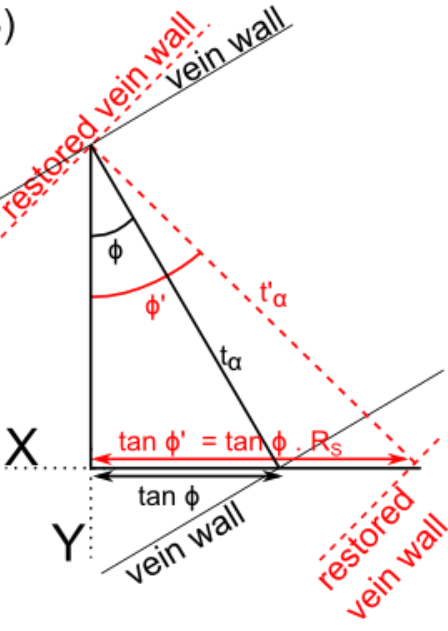

dolomite fibre

restored dolomite fibre

Fig. A.1. Geometric relations to calculate original vectors before homogeneous shortening. Reconstructed vectors are denoted with a prime. (A) Illustrated angles are the layer inclination $\alpha$ and the obliquity angle of the dolomite fibres $B$. (B) The orthogonal thickness of the veins, $t^{\prime}{ }_{\alpha}$ is reconstructed using the deduced $R_{S}$ for the four folds in Fig. 11. The angle $\delta$ represents the smallest angle between $t_{\alpha}$ and the $Y Z$ plane of the strain ellipsoid.

\section{Reference List}

Annels, A.E., 1989. Ore genesis in the Zambian Copperbelt, with particular reference to the Northern Sector of the Chambishi Basin, in: Boyle, R.W., Brown, A.C., Jeferson, C.W., Jowett, E.C., Kirkham, R.V. (Eds.), Sediment-Hosted Stratiform Copper Deposits. Geological Society of Canada, pp. 427-452.

Barker, S., Cox, S., Eggins, S., Gagan, M., 2006. Microchemical evidence for episodic growth of antitaxial veins during fracture-controlled fluid flow. Earth and Planetary Science Letters 250, 331-344.

Bastida, F., Aller, J., Bobillo-Ares, N.C., Toimil, N.C., 2005. Fold geometry: a basis for their kinematical analysis. EarthScience Reviews 70, 129-164.

Bastida, F., Bobillo-Ares, N.C., Aller, J., Toimil, N.C., 2003. Analysis of folding by superposition of strain patterns. Journal of Structural Geology 25, 1121-1139.

Blenkinsop, T.G., 2000. Deformation Microstructures and Mechanisms in Minerals and Rocks. Kluwer Academic Publishers, Dordrecht.

Bobillo-Ares, N.C., Aller, J., Bastida, F., Lisle, R.J., Toimil, N.C., 2006. The problem of area change in tangential longitudinal strain folding. Journal of Structural Geology 28, 1835-1848.

Bobillo-Ares, N.C., Bastida, F., Aller, J., Lisle, R.J., 2009. An approach to folding kinematics from the analysis of folded oblique surfaces. Journal of Structural Geology 31, 842-852.

Bons, P.D., Elburg, M.A., Gomez-Rivas, E., 2012. A review of the formation of tectonic veins and their microstructures. Journal of Structural Geology 43, 3362.

Bons, P.D., Montenari, M., 2005. The formation of antitaxial calcite veins with well-developed fibres, Oppaminda Creek, South Australia. Journal of Structural Geology 27, 231-248.

Brems, D., Muchez, P., Sikazwe, O., Mukumba, W., 2009. Metallogenesis of the Nkana copper-cobalt South Orebody, Zambia. Journal of African Earth Sciences 55, 185-196.

Bull, S., Selley, D., Broughton, D., Hitzman, M., Cailteux, J., Large, R., McGoldrick, P., 2011. Sequence and carbon isotopic stratigraphy of the Neoproterozoic Roan Group strata of the Zambian copperbelt. Precambrian Research 190, 70-89.

Cailteux, J.L.H., Kampunzu, A.B.H., Batumike, M.J., 2005. Lithostratigraphic position and petrographic characteristics of R.A.T. ("Roches Argilo-Talqueuses") Subgroup, Neoproterozoic Katangan Belt (Congo). Journal of African Earth Sciences 42, 82-94.

Couples, G.D., Lewis, H., Tanner, P.W.G., 1998. Strain partitioning during flexural-slip folding. Geological Society, London, Special Publications 127, 149-165.

Cox, S.F., Wall, V.J., Etheridge, M.A., Potter, T.F., 1991. Deformational and metamorphic processes in the formation of mesothermal vein-hosted gold deposits examples from the Lachlan Fold Belt in central Victoria, Australia 6, 391-423.

Croaker, M.R.D., 2011. Nkana-Mindola sediment-hosted Cu-Co deposit, Zambia. PhD Thesis, University of Tasmania.

Davis, N.E., Kronenberg, A.K., Newman, J., 2008. Plasticity and diffusion creep of dolomite. Tectonophysics 456, 127146.

De Roo, J.A., Weber, K., 1992. Laminated veins and hydrothermal breccia as markers of low-angle faulting, Rhenish Massif, Germany. Tectonophysics 208, 413-430.

Debruyne, D., Balcaen, L., Vanhaecke, F., Muchez, P., 2013. REEY characteristics in hydrothermal gangue carbonates within the sediment-hosted Nkana-Mindola Cu-Co deposit (Zambia) and in two polymetallic vein-type deposits (Kipushi and Dikulushi, Democratic Republic of Congo), in: Johnsson, E. (Ed.), Minerals for a High-Tech World. 12th Biennial SGA Meeting. pp. 1251-1254.

Dickson, J.A.D., 1966. Carbonate identification and genesis as revealed by staining. Journal of Sedimentary Research $36,491-505$.

Dickson, J.A.D., 1993. Crystal growth diagrams as an aid to interpreting the fabrics of calcite aggregates. Journal of Sedimentary Research 63, 1-17.

Evans, M.A., Fischer, M.P., 2012. On the distribution of fluids in folds: A review of controlling factors and processes. Journal of Structural Geology 44, 2-24.

Fletcher, R., 1974. Wavelength selection in the folding of a single layer with power-law rheology. American Journal of Science 274, 1029-2043. 
Fletcher, R.C., 2005. Instability of an anisotropic power-law fluid in a basic state of plane flow. Journal of Structural Geology 27, 1155-1167.

Forde, A., Bell, T.H., 1994. Late structural control of mesothermal vein-hosted gold deposits in central Victoria, Australia: Mineralization mechanisms and exploration potential. Ore Geology Reviews 9, 33-59.

Fossen, H., 2010. Structural Geology, 1st ed. Cambridge University Press, New York.

François, A., 1974. Stratigraphie, tectonique et minéralisations dans l'arc cuprifère du Shaba (République du Zaïre). Annales de la Société géologique de Belgique Publicatio, 79-101.

Frehner, M., Schmalholz, S.M., 2006. Numerical simulations of parasitic folding in multilayers. Journal of Structural Geology 28, 1647-1657.

Hilgers, C., Koehn, D., Bons, P.D., Urai, J.L., 2001. Development of crystal morphology during unitaxial growth in a progressively widening vein: II. Numerical simulations of the evolution of antitaxial fibrous veins. Journal of Structural Geology 23, 873-885.

Hilgers, C., Urai, J.L., 2002. Microstructural observations on natural syntectonic fibrous veins: implications for the growth process. Tectonophysics 352, 257-274.

Hippertt, J., Tohver, E., 2002. Interaction of flexural shear, S-C fabrics, and oblique shear during folding of micaceous quartzite 24, 1087-1099.

Hitzman, M.W., Broughton, D., Selley, D., Woodhead, J., Wood, D., Bull, S., 2012. The Central African Copperbelt: Diverse stratigraphic, structural, and temporal settings the world's largest sedimentary copper district. Society of Economic Geologists Special Publication 16, 487-514.

Hobbs, B., Regenauer-Lieb, K., Ord, A., 2008. Folding with thermal-mechanical feedback. Journal of Structural Geology 30, 1572-1592.

Hobbs, B., Regenauer-lieb, K., Ord, A., 2010. Folding with thermal mechanical feedback: Another reply. Journal of Structural Geology 32, 131-134.

Hobbs, B.E., Ord, A., 2012. Localized and chaotic folding: the role of axial plane structures. Philosophical transactions of the Royal Society Series A: Mathematical, physical, and engineering sciences 370, 1966-2009.

Hobbs, B.E., Ord, A., Regenauer-Lieb, K., 2011. The thermodynamics of deformed metamorphic rocks: $A$ review. Journal of Structural Geology 33, 758-818.

Hodgson, C., 1989. The structure of shear-related, vein-type gold deposits: a review. Ore Geology Reviews 4, 231273.

Huang, K.-P., Chang, K.-J., Wang, T.-T., Jeng, F.-S., 2010. Buckling folds of a single layer embedded in matrix Folding behavior revealed by numerical analysis. Journal of Structural Geology 32, 960-974.
Hudleston, P.J., Holst, T.B., 1984. Strain analysis and fold shape in a limestone: implications for layer rheology. Tectonophysics 106, 321-347.

Hudleston, P.J., Lan, L., 1993. Information from fold shapes. Journal of Structural Geology 15, 153-264.

Hudleston, P.J., Srivastava, H.B., 1997. Strain and crystallographic fabric pattern in a folded calcite vein: the dependence on initial fabric, in: Evolution of Geological Structures in Micro- to Macro-Scales. Springer Science/Business Media Dordrecht, Devon, pp. 259-271.

Hudleston, P.J., Treagus, S.H., 2010. Information from folds: A review. Journal of Structural Geology 32, 2042-2071.

Hudleston, P.J., Treagus, S.H., Lan, L., 1996. Flexural flow folding: Does it occur in nature? Geology 24, 203-206.

John, T., Schenk, V., Mezger, K., Tembo, F., 2004. Timing and PT evolution of whiteschist metamorphism in the Lufilian Arc-Zambezi Belt orogen (Zambia): Implications for the assembly of Gondwana. The Journal of Geology 112, 71-90.

Kocher, T., Mancktelow, N.S., Schmalholz, S.M., 2008. Numerical modelling of the effect of matrix anisotropy orientation on single layer fold development. Journal of Structural Geology 30, 1013-1023.

Kocher, T., Schmalholz, S.M., Mancktelow, N.S., 2006. Impact of mechanical anisotropy and power-law rheology on single layer folding. Tectonophysics 421, 71-87.

Koehn, D., Passchier, C.W., 2000. Shear sense indicators in striped bedding-veins. Journal of Structural Geology 22, 1141-1151.

Lan, L., Hudleston, P., 1996. Rock rheology and sharpness of folds in single layers. Journal of Structural Geology 18, 925-931.

Lisle, R., 1992. Strain estimation from flattened buckle folds. Journal of Structural Geology 14, 369-371.

Lisle, R.J., 1999. Predicting patterns of strain from threedimensional fold geometries: neutral surface folds and forced folds. Geological Society, London, Special Publications 169, 213-221.

Llorens, M.-G., Bons, P.D., Griera, A., Gomez-Rivas, E., Evans, L., 2013. Single layer folding in simple shear. Journal of Structural Geology 50, 209-220.

Mandl, G., 1987. Tectonic deformation by rotating parallel faults: the "bookshelf" mechanism. Tectonophysics 141, 277-316.

McGowan, R.R., Roberts, S., Boyce, A.J., 2006. Origin of the Nchanga copper-cobalt deposits of the Zambian Copperbelt. Mineralium Deposita 40, 617-638.

Mendelsohn, F., 1961a. The Geology of the Northern Rhodesian Copperbelt. MacDonald, London.

Mendelsohn, F., 1961b. Roan Antelope, in: Mendelsohn, F. (Ed.), The Geology of the Northern Rhodesian Copperbelt. pp. 351-405. 
Muchez, P., Brems, D., Clara, E., De Cleyn, A., Lammens, L., Boyce, A., De Muynck, D., Mukumba, W., Sikazwe, O., 2010. Evolution of Cu-Co mineralizing fluids at Nkana Mine, Central African Copperbelt, Zambia. Journal of African Earth Sciences 58, 457-474.

Mukhopadhyay, D., 1965. Effects of compression on concentric folds and mechanism of similar folding. Journal of the Geological Society of India 6, 27-41.

Nollet, S., Hilgers, C., Urai, J.L., 2006. Experimental study of polycrystal growth from an advecting supersaturated fluid in a model fracture. Geofluids 6, 185-200.

Nollet, S., Koerner, T., Kramm, U., Hilgers, C., 2009. Precipitation of fracture fillings and cements in the Buntsandstein (NW Germany). Geofluids 9, 373-385.

Oliver, N.H.S., Bons, P.D., 2001. Mechanisms of fluid flow and fluid-rock interaction in fossil metamorphic hydrothermal systems inferred from vein-wallrock patterns, geometry and microstructure. Geofluids 1, 137-162.

Passchier, C.W., Trouw, R.A.J., 2005. Microtectonics. Springer, Berlin, Heidelberg.

Porada, H., Berhorst, V., 2000. Towards a new understanding of the Neoproterozoic-Early Palaeozoic Lufilian and northern Zambezi Belts in Zambia and the Democratic Republic of Congo. Journal of African Earth Sciences 30, 727-771.

Ragan, D.M., 2009. Structural Geology: An Introduction to Geometrical Techniques, 4th ed. Cambridge University Press.

Rainaud, C., Master, S., Armstrong, R.A., Phillips, D., Robb, L.J., 2005. Monazite U-Pb dating and 40Ar-39Ar thermochronology of metamorphic events in the Central African Copperbelt during the Pan-African Lufilian Orogeny. Journal of African Earth Sciences 42, 183-199.

Ramsay, J., 1962. The geometry and mechanics of formation of " similar" type folds. The Journal of Geology.

Ramsay, J., 1974. Development of chevron folds. Geological Society of America Bulletin 85, 1741-1754.

Ramsay, J.G., 1967. Folding and Fracturing of Rocks. McGrawHill, Inc.

Schmalholz, S.M., 2006. Scaled amplification equation: A key to the folding history of buckled viscous single-layers. Tectonophysics 419, 41-53.

Schmalholz, S.M., 2008. 3D numerical modeling of forward folding and reverse unfolding of a viscous single-layer: Implications for the formation of folds and fold patterns. Tectonophysics 446, 31-41.

Schmalholz, S.M., Podladchikov, Y.Y., 1999. Buckling versus Folding: Importance of Viscoelasticity. Geophysical Research Letters 26, 2641-2644.

Schmalholz, S.M., Podladchikov, Y.Y., 2000. Finite amplitude folding: transition from exponential to layer length controlled growth. Earth and Planetary Science Letters 179, 363-377.
Schmalholz, S.M., Podladchikov, Y.Y., 2001. Strain and competence contrast estimation from fold shape. Tectonophysics 340, 195-213.

Schmalholz, S.M., Schmid, D.W., 2012. Folding in power-law viscous multi-layers. Philosophical transactions of the Royal Society, Series A: Mathematical, physical, and engineering sciences 370, 1798-826.

Schmid, D.W., Podladchikov, Y.Y., 2006. Fold amplification rates and dominant wavelength selection in multilayer stacks. Philosophical Magazine 86, 3409-3423.

Schmid, D.W., Schmalholz, S.M., Mancktelow, N.S., Fletcher, R.C., 2010. Comment on "Folding with thermalmechanical feedback". Journal of Structural Geology 32, 127-130.

Schuh, W., Leveille, R., Fay, I., North, R., 2012. Geology of the Tenke-Fungurume Sediment-Hosted Strata-Bound Copper-Cobalt District, Katanga, Democratic Republic of Congo, in: Hedenquist, J.W., Harris, M., Camus, F. (Eds.), Society of Economic Geologists Special Publication 16. pp. 269-302.

Selley, D., Broughton, D., Scott, R.J., Hitzman, M., Bull, S.W., Large, R.R., McGoldrick, P.J., Croaker, M., Pollington, N., Barra, F., 2005. A new look at the geology of the Zambian Copperbelt. Economic Geology 100, 965-1000.

Shimamoto, T., Hara, I., 1976. Geometry and strain distribution of single-layer folds. Tectonophysics 30, 134.

Sillitoe, R.H., Perelló, J., García, A., 2010. Sulfide-bearing veinlets throughout the stratiform mineralization of the Central African Copperbelt: temporal and genetic implications. Economic Geology 105, 1361-1368.

Srivastava, D.C., Shah, J., 2006. A rapid method for strain estimation from flattened parallel folds. Journal of Structural Geology 28, 1-8.

Srivastava, D.C., Shah, J., 2008. The "isogon rosette" method for rapid estimation of strain in flattened folds. Journal of Structural Geology 30, 444-450.

Sweeney, M., Turner, P., Vaughan, D.J., 1986. Stable isotope and geochemical studies in the role of early diagenesis in ore formation, Konkola Basin, Zambian copper belt. Economic Geology 81, 1838-1852.

Tanner, G.P.W., 1989. The flexural-slip mechanism. Journal of Structural Geology 11, 635-655.

Tanner, P.W.G., 1992. Morphology and geometry of duplexes formed during flexural-slip folding. Journal of Structural Geology 14, 1173-1192.

Thieme, J.G., Johnson, R.L., 1981. Geological map of the Republic of Zambia. Geological Survey of Zambia, Lusaka. Scale 1:1000000.

Toimil, N.C., Fernández, F.J., 2007. Kinematic analysis of symmetrical natural folds developed in competent layers. Journal of Structural Geology 29, 467-480. 
Toimil, N.C., Griera, A., 2007. Influence of viscosity contrast and anisotropy on strain accommodation in competent layers. Journal of Structural Geology 29, 787-801.

Torremans, K., Gauquie, J., Boyce, A.J., Barrie, C.D., Dewaele, S., Sikazwe, O., Muchez, P., 2013. Remobilisation features and structural control on ore grade distribution at the Konkola stratiform $\mathrm{Cu}$-Co ore deposit, Zambia. Journal of African Earth Sciences 79, 10-23.

Treagus, J.E., Treagus, S.H., 1981. Folds and the strain ellipsoid: a general model. Journal of Structural Geology 3, 1-17.

Treagus, S.H., 2003. Viscous anisotropy of two-phase composites, and applications to rocks and structures. Tectonophysics 372, 121-133.

Treagus, S.H., Fletcher, R.C., 2009. Controls of folding on different scales in multilayered rocks. Journal of Structural Geology 31, 1340-1349.

Twiss, R.J., Moores, E.M., 2007. Structural Geology, 2nd ed. W. H. Freeman and Company.

Urai, J.L., Williams, P.F., van Roermund, H.L.M., 1991. Kinematics of crystal growth in syntectonic fibrous veins. Journal of Structural Geology 13, 823-836.
Van den Kerkhof, A.M., Hein, U.F., 2001. Fluid inclusion petrography. Lithos 55, 27-47.

Van Wilderode, J., Muchez, P., Elburg, M.A., Vanhaecke, F., 2013. Sr and Nd isotope ratio data of the Nkana and Kipushi deposits and of basement to the Central African Copperbelt, in: E. Johnsson (Ed.), Minerals for a HighTech World. 12th Biennial SGA Meeting. pp. 702-705.

Williams, P.F., Urai, J.L., 1989. Curved vein fibres: an alternative explanation. Tectonophysics 158, 311-333.

Windh, J., 1995. Evolution of an auriferous vein system during progressive deformation. Economic Geology 90, 17641775.

Zagorčev, I.S., 1993. The geometrical classification of folds and distribution of fold types in natural rocks. Journal of Structural Geology 15, 243-251.

Zhang, Y., Hobbs, B.E., Jessell, M.W., 1993. Crystallographic preferred orientation development in a buckled single layer: a computer simulation. Journal of Structural Geology 15, 265-276. 